\title{
CORRESPONDENCIA ERUDITA ENTRE MAYANS Y MURATORI
}

\author{
Antonio MESTRE \\ Universitat de València
}

\begin{abstract}
Resumen
Ludovico Muratori, uno de los pilares de la Ilustración italiana, ejerció un notable influjo sobre la cultura española en general y, muy en particular, sobre Gregorio Mayans, cuya concepción de la religiosidad tenía grandes afinidades con la del Biliotecario de Modena. Antonio Mestre estudia y edita la correspondencia de Muratori con Mayans entre 1739 y 1743 centrada en tres aspectos: la epigrafía latina; el embargo que sufrió la edición mayansiana de la Censura de historias fabulosas de Nicolás Antonio; y, muy especialmente, consideraciones sobre el nivel cultural de los españoles y la política cultural del Gobierno.
\end{abstract}

\begin{abstract}
Ludovico Muratori, one of the pillars of the Italian Illustration, exercised a notable influence on Spanish culture on the whole and very in particular on Gregorio Mayans, whose conception of the religiosity had great affinities with the librarian of Modena. Antonio Mestre studies and edits the correspondence of Muratori with Mayans between 1739 and 1743 focus on three aspects: the Latin inscriptions; the embargo that Mayan's edition suffered of Censura de historias fabulosas by Nicolás Antonio and, very especially, considerations about the cultural level of the Spaniards and the governmental cultural policy.
\end{abstract}

En 1972 presenté una larga ponencia al Convegno Internazionale di Studi Muratoriani de Modena. El título, Muratori y la cultura española, era muy ambicioso y el trabajo, basado en las traducciones de Muratori al castellano y la amplísima correspondencia mayansiana, demostró que la figura intelectual del bibliotecario de Modena tuvo una gran repercusión en España'. Ese descubrimiento nació de la correspon-

1. A. MESTRE, «Muratori y la cultura española», en Atti del Convegno Internazionale di Studi Muratoriani. La fortuna di L. A. Muratori, Modena 1972; impreso en Firenze 1975, pp. 173-220. 
dencia cruzada entre Muratori y Mayans, que se conserva en el fondo Serrano Morales del Ayuntamiento de Valencia. Cuando Enrique Giménez me pidió colaboración para un número monográfico de la Revista de Historia Moderna de la Universidad de Alicante sobre las relaciones culturales hispano-italianas, me pareció interesante ofrecer la correspondencia íntegra entre los dos eruditos. Mi intención, en este caso, es poner a disposicion del lector interesado un testimonio de las relaciones en el campo de la erudición. Conviene, por tanto, iniciar con unas breves reflexiones sobre las circuntancias que propiciaron el encuentro literario.

La correspondencia se inició en 1739. Mayans, que era bibliotecario real desde 1733, había desarrollado una gran actividad cultural en la Corte, donde había suscitado polémicas y nunca había encontrado el favor del poder. De familia austracista, llegó a la Real Biblioteca gracias al apoyo del jesuita exiliado cardenal Alvaro Cienfuegos, otro austracista, que avaló al erudito ante el confesor del rey Guillermo Clarke. Pero también otros personajes de la Corte apoyaron la candidatura de Mayans y, entre ellos, sobresale José Octavio Bustanzo, encargado de negocios de Génova, bien relacionado con el mundo cultural español e italiano. Poseemos muchos testimonios de su conocimiento del mundo cultural italiano: visita y trato con el librero Repetto, instalado en Madrid, que importaba libros de Italia, su correspondencia con Muratori y después con el nuncio en España Enrico Enríquez. Y en cuanto a sus relaciones con los grupos de la Corte, baste recordar que colaboró económicamente con el embajador británico Benjamín Keene en la edición de Epistolarum libri XII del deán de Alicante Manuel Martí (1735). De ahí que Mayans quisiera dejar constancia de su gratitud a Bustanzo con la dedicatoria latina de E. Martini, decani alonensis, vita (1735). Por lo demás, la amistad de Bustanzo con Mayans fue constante y sin altibajos, como lo demuestra su cordial y continuada correspondencia ${ }^{2}$.

De creer a don Gregorio, la iniciativa de su correspondencia con Muratori partió del abate Guido Eustachio Lucarelli, de Regio de Modena, autor de unas Meditaciones sobre la Vida de san Geminiano, «criticando la vida de Sn. Geminiano escrita últimamente por un fulano Rossi», que envió tanto a Bustanzo como a Mayans, deseando conocer su juicio (15-VIII- y 10-X-1739). Da la impresión de que buscaba un erudito español que pudiera informar a Muratori sobre los trabajos de epigrafía latina, para completar las noticias relativas a Hispania y Lusitania en su Novus thesaurus veterum inscriptionum in praecipuis earumdem collectionibus hactenus praetermissarum. En este caso, Bustanzo, dada su amistad con Mayans y el alto concepto que tenía de la capacidad intelectual del valenciano, facilitó el nombre de don Gregorio. Así parece deducirse de la correspondencia conservada. No encontré carta alguna de Mayans a Lucarelli, ni del abate italiano al olivense. Pero en ese sentido apuntan los datos que poseemos, como unas palabras de la primera carta de Mayans a Muratori: "Illustrissimum virum Guidonem Eustachium Lucarellum, cui ego debeo amicitiam tuam, meo nomine saluta» (13-IV-1739). Estas palabras fueron escritas por don Gregorio cuando todavía residía en Madrid. Pero, en agosto, mientras esperaba noticias del viaje del erudito a Oliva, Bustanzo escribía: «Me anticipo...con el motivo de remitirle la adjunta cartica, que he recibido de Modena, dentro de una de mi amigo Dn.

2. La correspondencia entre Mayans y Bustanzo se conserva en el Colegio de Corpus Christi (BAHM), y para el caso que nos ocupa interesa el volumen 40. 
Guido Eustachio Lucarelli, por lo que discurro que sea del Sr. Muratori» (1-VIII1739). De hecho, sin Bustanzo, la correspondencia Mayans-Muratori hubiera sido inviable. Así lo decía muy ufano el mismo Bustanzo: «essotro día vino el embiado de Modena, que es el conde Dn. Carlos Cassio, íntimo amigo (consiguientemente hombre literato i de buen gusto) de nuestro Sr. Muratori, de quien me ha traído una carta mui llena de finas expressiones acia mí. Sin mucha vanidad puedo decir que las merezco pues he sido, aunque materialmente, el medio del conocimiento i correspondencia que tiene de Vm.» (13-V-1741).

Estas circunstancias exteriores y la buena acogida de Mayans, por supuesto. Porque se ha insistido mucho, al hablar de la Ilustración española, en el influjo francés propiciado por la dinastía borbónica, los jesuitas franceses confesores de los monarcas, las Reales Academias de la Lengua y, después, de la Historia y del mismo Feijoo y los Diaristas. Sin embargo, sin despreciar la cultura gala (recuérdese su admiración por Bossuet o Fleury), Mayans era un humanista con evidente influjo italiano. No en vano Manuel Martí, su mentor intelectual, había residido durante una década en Roma y afirmaba «Italiam, literarum, studiorumque altricem, eruditionis fastigium et columen, ingeniorumque proventu regionum omnium feracissimam» ${ }^{3}$. Y si Martí, amigo de Gravina, Fabretti o Noris, habla de Muratori en 1722 (a quien transmite cordiales saludos de Felipe Bolifón) y da saludos para Felipe Buonarroti y Scipione Maffei $^{4}$, el joven Mayans pudo comprar las obras de Noris y leer Del buon gusto nelle arti e nelle science de Muratori en 1732. El libro le había sido proporcionado por el oratoriano Felipe Seguer y despertó el interés del erudito que animó a sus amigos a leer la obra. Pero él personalmente buscó con afán otros libros de Muratori, como Della carità cristiana, Del goberno della peste y, sobre todo, Filosofia Morale cuya traducción había emprendido en $1736^{5}$. En consecuencia el erudito de Oliva estaba bien dispuesto a entrar en relación con Muratori.

Las circunstancias expuestas explicarían el hecho de que Muratori, antes de iniciar la correspondencia, tuviera en sus manos los libros más importantes de Mayans. Así empieza la primera carta del bibliotecario de Modena: «Teneo libros tuos...et eos quidem mihi perquam caros, sed longe cariores, quod illos volueris tui erga me amoris testes» (10-III-1739). Es decir, Mayans, o en su lugar Bustanzo, había enviado la Vida de Antonio Agustín (1734), Vida de Miguel de Cervantes Saavedra (1737), Orígenes de la lengua española (1737) y, por supuesto, Epistolarum libri VI (1732). Muratori celebró la Vida de Antonio Agustín, «magni viri», o del graciosísimo Cervantes y lamentó no haber conocido los Orígenes de la lengua española, que le hubieran ayudado para su disertación sobre el origen de la lengua italiana que incluyó en Antiquitates Italicae Medii Aevi y, después de manifestar su sorpresa ante el espléndido latín de Martí y de Mayans, abordaba los temas que centrarán las reflexiones posteriores: colección de inscripciones latinas, nivel cultural de los españoles, publicaciones de textos antiguos españoles. Son aspectos que marcarán la pauta de la correspondencia posterior.

3. E. Martinus Antonio F. Zondadario, VIII Idus Ian. 1705, Epistolarum libri XII, Madrid 1735, lib. IV, ep. 9

4. E. Martinus C. Rinuccino, Eid. Iun. 1722, Ibíd., lib. XI, ep. 7

5. Mayans a J. Cabrera, 31-X-1736, BAHM, 4. 
En primer lugar, la epigrafía. Muratori, que estaba preparando su Novus Thesaurus, encontró en las cartas latinas mayansianas algunas inscripciones que no aparecían en las grandes colecciones de Grutero, Reinesio, Fabretti..., y que pensaba incluir en su obra. En plena coherencia, solicitaba de la amabilidad del valenciano que, en caso de poseer algunas inscripciones desconocidas, se las enviase (10-III-1739).

Mayans se mostró amable y servicial desde el primer momento. Como, vistas las circunstancias culturales de la Corte, había decidido abandonar su cargo de bibliotecario real, ya había enviado su biblioteca a Oliva y con ella sus manuscritos, «unde inscriptiones aliquas ineditas tibi possem describere; quod libenter faciam quam primum illuc pervenero» (13-IV-1739). En consecuencia aconsejó a Muratori que dejase la edición de las españolas para el último volumen. Y, por supuesto, manifestó el deseo de conocer qué libros había utilizado el bibliotecario de Modena para su colección, al tiempo que le indicaba dónde encontrar las publicadas pertenecientes a cada región: Andrés Resende para Portugal, Pedro Antonio Beuter, Francisco Diago, Gaspar Escolano y Vicente del Olmo para Valencia, Pons Icart y Antonio Agustín para Tarragona, Jerónimo Pujades y Pedro Marca para Cataluña, Rodrigo Caro para Sevilla, Pedro Díaz de Ribas para Córdoba, Juan Bautista Suárez y Jerónimo de la Concepción para Cádiz, Fernando de Mendoza y Francisco Bermúdez de Pedraza para Granada, sin olvidar la obra de Ambrosio de Morales de quien las tomó Adolfo Ocón ${ }^{6}$.

Por supuesto, no todas las inscripciones transcritas por los mencionados autores merecen el crédito de auténticas y algunas exigen correcciones. Asimismo, Mayans aconseja la consulta de la colección conservada en la biblioteca Barberini de Roma, donación del obispo de Salamanca, Juan Bautista Valenzuela Velázquez, y que había sido utilizada por Nicolás Antonio. E insiste, además, en la necesidad de mantener una actitud crítica, pues muchas inscripciones, «quas impostor ille Cyriacus Anconitanus confixit», han sido aceptadas por historiadores posteriores, entre ellos el mismo Grutero, y señala como ejemplo las inscripciones sobre la persecución de Nerón en España, que nadie ha visto. Así, como prueba de su buena voluntad, le transcribe "paucas istas inscriptiones», con el deseo de enviarle otras cuando conozca las fuentes utilizadas por Muratori. Inscripciones, que pertenecientes a muy diversas partes de la península, fueron utilizadas por Muratori y, como indicaré en la transcripción de las cartas, están recogidas por Hübner.

Muratori quedó gratamente sorprendido y se apresuró a responder a su interlocutor. Además de anunciar la aparición del primer volumen del Novus thesaurus, confesaba su desconocimiento de la bibliografía sobre inscripciones indicada por el valenciano, al tiempo que precisaba las fuentes de que se había servido: Grutero y las fichas del P. Cattaneo, Donius, Ocón y Valenzuela. En consecuencia, si Mayans tuviera algunas inscripciones inéditas, le haría un gran favor, si se dignase enviarlas. De las ya recibidas, algunas habían sido publicadas por Grutero, las inéditas «sub tuo nomine proferentur» (25-VI-1739).

Mayans no respondió de momento, pero actuó con generosidad. Dadas sus buenas relaciones con los hombres de letras portugueses, tenía buen conocimiento de los trabajos históricos en curso. Así, Francisco de Almeida, Censor de la Academia de la

6. Datos concretos sobre estos epigrafistas en la Praefatio de Hübner al C.I.L. 
Historia, le envió De antiquitatibus conventus Bracaraugustani libri quinque, del P. Contador de Argote. Y don Gregorio renunció al regalo para remitirlo, desde Madrid, a Muratori. Así lo expresaba el mismo erudito: «D. Francisco de Almeida me ha embiado algunos libritos, que llegarán esta semana, i entre ellos uno, De antiquitatibus conventus Bracaraugustani, con muchas inscripciones que se queda en Madrid para que lo lleve a Muratori uno de la familia del Nuncio, el qual va con su legación a Bolonia, poco distante de Modena. No puede embiarse por correo extraordinario, porque ai orden estrecha de que no se lleve, ni aún cartas, sino las del rei»? ${ }^{7}$. Fue Martínez Pingarrón, el confidente de Mayans en Madrid, el encargado de recoger el paquete y entregarlo a Bustanzo para su envío a Modena.

Este proceso, aquí narrado, resulta confuso en el Novus Thesarus, porque en el Appendix del volumen IV, se introdujo un error, calificando el libro como de conventus caesaraugustani. Pero Muratori sí agradeció el favor, pues le proporcionaba el conocimiento de muchas inscripciones relativas a la Lusitania, que desconocía (26-V1740).

Esta vez, don Gregorio respondió con amplitud y su carta constituye el mejor testimonio del profundo conocimiento que tenía de la evolución de los estudios epigráficos: Ciriaco Anconitano, Amancio y Apiano, Andrés Schott, Panvinio... El origen de la mayoría de los errores radica, a su juicio, en las fichas manuscritas de Ciriaco Anconitano, que otros autores serios copiaron, pasando de mano en mano, y muchos fabuladores (Ocampo, Pellicer) justificaron sus juicios con Ciriaco; y otros serios (como Morales), que manifestaron sus dudas, acabaron utilizándolas. En este proceso, el engaño llegó a Andrés Schott y al mismo Grutero. Mayans manifestó el deseo de la redacción de un índice donde pudiera verse con certeza cuáles eran auténticas y cuáles fingidas, porque España, que, después de Italia, posee el mayor número de inscripciones, no necesita de falsificaciones. Y establecía un criterio muy riguroso: todas las inscripciones, publicadas por Ciriaco, Amancio y Apiano, son falsas, a no ser que otro autor probo y científico lo confirme (19-VIII-1740).

En esta carta esboza Mayans una historia de los colectores de inscripciones latinas. El interés despertado desde el humanismo renacentista, con el afán de descubrir los secretos de la antiguiedad clásica, encontró un campo apasionante en la epigrafía. Como era lógico, también surgieron falsificadores. Dada su actitud crítica contra todo género de falsificaciones, el erudito de Oliva habla de los grandes colectores y de los autores que, de buena o mala fe, publicaron falsas inscripciones. Su animosidad se centra contra Ciriaco Anconitano, que continúa siendo sospechoso. Pero también da su juicio sobre Amancio y Apiano, Strada, Schott, Ocón, Grutero, Florián de Ocampo, Morales, y tantos otros, cuyo análisis pormenorizado no procede ahora ${ }^{8}$. Este criterio riguroso fue mantenido por Mayans en cartas posteriores, más amplias y meditadas, como la enviada al Director de la Academia Latina de Jena, Johann E. I. Walch, donde la historia de los colectores de inscripciones y su valoración aparece más perfilada. Si estos juicios han sido confirmados, o más bien superados, por estudios poste-

7. G. Mayans a J.A. Mayans, 21-X-1739, BAHM, 145.

8. Todas las inscripciones enviadas a Muratori, según aparecen en las cartas, llevarán en su transcripción la referencia concreta a la obra de Hübner. 
riores, puede constatarse con la lectura de la rigurosa Praefatio de Hübner a su Inscriptiones Hispaniae latinae (1869).

Muratori retrasó la respuesta debido a sus enfermedades, en especial de los ojos, «ex iam familiari vitio laborantibus». La carta mayansiana, decía, le llegó por medio de Bustanzo, y contenía la amplia disertación sobre las antiguas inscripciones de Hispania, «quam multa voluptate legi». En efecto, explica, cuando redacte el índice general de Grutero y de los otros colectores que, según deseo de Mayans, piensa llevar a cabo, tendrá presente la carta del valenciano. Sin embargo, no quisiera que don Gregorio hubiera calificado de impostor a Ciriaco Anconitano, pues el mismo Muratori dispuso de las fichas y ex iis, quae ipse vidit, nihil est non germanum atque legitimum», al tiempo que reconoce el mérito del P. Contador de Argote sobre Braga, que utilizará con provecho (8-II-1741).

Todavía en el campo de las inscripciones, Mayans aportó nuevos datos y, si no conociera la perspicacia del bibliotecario de Modena, todavía añadiría algunas reflexiones. Así, además de copiar la inscripción ibérica de la ermita de la Virgen del Cid, que había editado "aliquantulum depravatam» Gaspar Escolano, exponía su criterio sobre el número de letras del alfabeto ibérico. Y, aprovechando la cercanía, transcribe su lectura de algunas inscripciones del barrio del Salvador de Sagunto, Fuente de Encarroz, Daimus y Valencia (27-V-1741).

En relación con la crítica, aunque centrada en las ficciones en el campo de la historia eclesiástica, aparecen las noticias sobre la Censura de historias fabulosas de Nicolás Antonio, que Mayans había editado a finales de 1742. El valenciano se apresuró a enviar un ejemplar a Muratori pidiendo su juicio. Pero, antes de recibir respuesta, volvió a escribir al bibliotecario de Modena, solicitando su ayuda ante la persecución llevada a cabo por el Consejo de Castilla y su Gobernador (el cardenal Molina) que apoyaban las fingidas láminas del Sacromonte de Granada. Don Gregorio buscó apoyo y protección en todas las personas de prestigio intelectual, o con poder, que pudiesen defenderle ante el Consejo o ante el cardenal. Se trataba, a su juicio, de intimidar a cuantos defendían la historia crítica y de apoyar y favorecer las supersticiones. En este sentido, el prestigio de Muratori como historiador, y sus numerosos protectores en Roma, podrían prestarle un valioso apoyo ante el cardenal y la opinión pública ${ }^{9}$.

Mayans escribió dos cartas a Muratori sobre el asunto del embargo de la Censura. En la primera, de 4 de mayo de 1743, contaba los pasos del embargo: la delación hecha por el canónigo Heredia, del Sacromonte, ante el Santo Ofico, que la despreció, la actitud del Consejo de Castilla aceptando el planteamiento favorable a las láminas condenadas por Inocencio XI, la intencionalidad política de acabar con la historia crítica; la actitud de sus amigos; sus protestas... Entre estas protestas sobresale la carta escrita por don Gregorio al papa Benedicto XIV (4-V-1743), de la que envía

9. Las referencias de Mayans al embargo de la Censura de historias fabulosas son constantes en las cartas de esas fechas. Pueden verse algunos ejemplos en G. MAYANS Y SISCAR, Epistolario XIV, Mayans y los altos cuadros de la magistratura y administración borbónica, I (1716-1750), edic. de A. Mestre Sanchis y P. Pérez García, Valencia 1996. Una síntesis del proceso y de las consecuencias en A. MESTRE SANCHIS, Ilustración y reforma de la Iglesia. Pensamiento político-religioso de don Gregorio Mayans y Siscar, Valencia 1968. 
una copia a Muratori, con la súplica de que exponga el caso a los cardenales amigos de Roma en busca de una recomendación ante el rey o ante el cardenal Molina. «Sin minus, actum in Hispania de literis». La segunda, fechada el 8 de junio del mismo año, entra en el problema histórico de fondo. A los hechos anteriormente narrados, añade las razones alegadas por Molina (antinacionalismo de Mayans por censurar a los escritores españoles y alabar a los extranjeros) y, sobre todo, plantea con rigor y método críticos las razones de la falsedad de todas las inscripciones del Sacromonte, las arábigas y las latinas.

La respuesta de Muratori no se encuentra entre sus cartas. Yo dudé que hubiera respondido, pero en el fondo mayansiano del Colegio de Corpus Christi encontré la solución. Gian Francesco Soli (sobrino del bibliotecario de Modena) deseaba una copia de toda la correspondencia cruzada entre su tío y Mayans, y por medio del Nuncio en Madrid (Enrico Enriquez) hizo llegar la solicitud al erudito de Oliva. Sus palabras son clarificadoras: «Conviene, che si sia smarrita alcuna lettera delle scritte dal mio signore zio a cotesto signore Mayans, perche non ho trovato fra le mandatemi tutte quelle, che io gli vidi scrivere... Fra le altre mi manca quella che gli scrisse dopo di aver ricevuta l'opera del signore cavalier Niccolò di Antonio sopra le Storie Favolose. Desidererei io poi, che V. abbia la bontà d'avvisarmi per mia istruzione se sia finita la persecuzione contro di esso signore Mayans, e se tutavia se ne viva ritirato alla patria» ${ }^{10}$.

Es decir, que Muratori recibió la Censura de historias fabulosas, que conoció la persecución que sufrió Mayans y que respondió al erudito de Oliva. La carta de Soli no indica con claridad si la carta del bibliotecario de Modena respondía al envío de la Censura o aludía también a las tribulaciones provocadas por el embargo. Por las referencias concretas a la persecución, parece deducirse que Muratori respondió a las atribuladas cartas en que el erudito de Oliva contaba el embargo de la Censura, de las Obras chronológicas de Mondéjar (todavía en prensa) y de los manuscritos del mismo Mayans. Lo cierto es que esta carta de Muratori era desconocida por su sobrino y tampoco se encuentra entre la correspondencia muratoriana del fondo Mayans. Lo más seguro es que no llegara a Oliva, pues don Gregorio no alude, que yo sepa, a esta carta que hubiera constituido un motivo de orgullo y satisfacción en momentos difíciles. Por otra parte, tampoco Bustanzo tenía noticias de Muratori: «Estoi impacientíssimo de no tener noticia del Sr. Muratori, a cuyas manos ni siquiera sé que haya llegado el dicho libro (Censura de historias fabulosas), siendo siete meses que se le llevó un tal abad Petrocchi, ministro del Sr. Duque de Modena» (20-VII-1743). Idénticas quejas en septiembre y octubre de 1743, aunque había solicitado noticias de Génova en repetidas ocasiones. Guerra y peste, añadía, obstaculizaban las comunicaciones. Quizás aquí haya que buscar las razones de la interrupción epistolar, pues años después también el Nuncio Enriquez lamentaba la ignorancia de noticias sobre Muratori.

De haberse limitado la correspondencia a los aspectos de epigrafía, y hasta de la Censura de historias fabulosas, el epistolario Mayans-Muratori carecería de relieve. Sería, con toda seguridad, de menor rigor y altura intelectual que la mantenida con

10. La carta de G. F. Soli, de 20-I-1752, se encuentra en BAHM, 87, y transcribí todo el texto en Muratori y la cultura española, p. 189 
Walch en la década de los años 50. Pero la correspondencia abordó, y desde el primer momento, un tema vidrioso: el nivel intelectual de los españoles y la política cultural del Gobierno. Cuando leyó Epistolarum libri sex, Muratori quedó sorprendido ante la belleza del latín de Martí y de Mayans. De esa manera comprendió que el valenciano «aeruginem a te excussisti» con que los españoles eran considerados en Italia. Ciertamente el mismo Muratori había celebrado el ingenio de los españoles en Del buon gusto... Pero por los escasos libros que llegaban a Italia se impuso el criterio de que en el siglo XVIII apenas existía la crítica y los españoles estaban todavía dominados por los prejuicios. Si él mismo pudiera entrar en la biblioteca de El Escorial, cuántos frutos podría ofrecer a la República Literaria, al tiempo que invitaba a Mayans a que, tomando por modelo Rerum italicarum scriptores, hiciera públicos los manuscritos inéditos (10-III-1739).

Las palabras del italiano constituían una invitación para que don Gregorio expusiera con claridad su pensamiento sobre la cultura española, que hoy conocemos bien. Desde que leyó, dice, Del buon gusto..., buscó los libros de Muratori: Della peste, Della carità cristiana y Filosofia morale, cuya traducción había iniciado, y haría pública, si los ingenios españoles no estuvieran tan corrompidos que los libros no bastan para su enmienda y sólo la Providencia de Dios puede solucionarlo. La razón de esta desconfianza: el enfermo no quiere curar. No hay premios para los beneméritos y, si alguien sobresale, todos se vuelven hacia él para vituperarlo, en vez de admirarlo. Y, para demostrar su aserto, expone su caso personal: sus trabajos jurídicos, sus proyectos de publicar las fuentes históricas (Carta a Patiño), autores ilustres conservados en la Real Biblioteca y en El Escorial (Nicolás Antonio, entre otros). Había hablado a sordos. En este sentido, narraba el ejemplo de la España primitiva, de Huerta y Vega que, basada en un falso cronicón, había sido publicada con el apoyo de las reales Academias de la Lengua y de la Historia y refrendada, pese a las pruebas aportadas por Mayans de que se trataba de un falso cronicón, por el mismo Consejo de Castilla ${ }^{11}$. En esas circunstancias, ¿para qué esforzarse? Sus palabras demuestran el desencanto del erudito: «I nunc, antiqua rudera lustra, inscriptiones erue, onera te pulvere, et in ipsa, si placet, monumenta conde te cum istis antiquitatis reliquiis, donec alii homines nascantur et alia sint feliciora tempora, quibus haec praestare in pretio sit». En consecuencia, como vio que no podía llevar a cabo ninguno de sus proyectos, decidió retirarse a su casa de Oliva y «philosophiae vacare» (13-IV-1739).

Muratori confirmó el concepto de Mayans, que había formado por sus libros, con la lectura de la carta que le había mostrado sus esfuerzos por restaurar las letras. ¿Cómo decayeron tanto los ingenios españoles? ¿Cómo es posible que, en un momento en que «literarum meliorum lux» se extiende en los otros países, los españoles amen la ignorancia de los siglos bárbaros y se deleiten con fábulas e impostores? El italiano se hacía eco de unas palabras de un crítico varón, que habiendo conocido bien los asuntos españoles, aseguraba que en España resultaba más grata la gente ignorante que la docta, e insinuaba que los inquisidores no perseguían las opiniones bárbaras que merecen el desprecio. Pero, al mismo tiempo, afirmaba con una audacia que debió halagar al valenciano: «Attamen si et Hispania nunc aleret sex alios viros

11. Una síntesis de estos hechos y las implicaciones políticas en A. MESTRE SANCHIS, Historia, fueros y actitudes políticas. Mayans y la historiografia del XVIII, Valencia 1970. 
tam probe animatos atque ad meliora laudabili zelo imperterrite currentes, qualis es $t u$, bene actum de literis etiam apud vos foret». En ese sentido, confesaba, es menester condolerse de la ausencia de mecenas que premien a quienes trabajan y, en consecuencia, apenas aparecen libros de erudición, mientras gozan de favor libros de teólogos, leguleyos y ascéticos. Al final, Muratori animaba a Mayans a esperar días mejores para sus proyectos: «Erit etiam dies aliquando tibi tuisque consiliis propitius» y lo invitaba a emprender la redacción de una Hispania sacra (si no la tenían los españoles) pues encontraría «copiosa mies» en los manuscritos de la Real Biblioteca (25VI-1739). Conviene observar la fecha, bastantes años antes de que el P. Flórez pensara en la redacción de la España Sagrada.

Mayans no debía confiar mucho en esas esperanzadoras palabras de Muratori y no contestó de momento a la carta, porque no se atrevía a interrumpir los trabajos del italiano, «nisi te iubente». Hizo enviar a Modena el libro del P. Contador de Argote y esperó nueva carta del bibliotecario de Modena. Así fue, y el 26 de mayo de 1740, Muratori, tras agradecer el libro, manifestaba su sorpresa: el valenciano había abandonado la Real Biblioteca. Parece, decía, como si los españoles sólo pretendieran promover guerras y conquistar nuevos reinos (evidente crítica a la política militar de los Borbones, promovida por Isabel de Farnesio) y, en consecuencia, las letras y sus cultivadores languidecían de frío y hambre. Si las cosas son así, "sortem tuam quam maxime doleo». ¡Qué uso hará Mayans de su ingenio y de su preparación intelectual, retirado en un desierto, sin bibliotecas! Muratori lamentaba que un hombre, nacido para honra y aumento de las letras, se viera obligado a permanecer oculto en un rincón de la tierra. «Utinam fallar». Y comunicaba que en Venecia y Florencia aparecieron revistas literarias que deseaban conocer las noticias españolas que merecieran el recuerdo, pero Italia y España estaban separadas por el cielo y por la guerra.

Esta vez el valenciano respondió ampliamente y agradeció los elogios de Muratori, a quien consideraba el más sabio de los italianos. Exponía su criterio sobre las inscripciones latinas, como ya hemos visto, pero indicaba, además, su desprecio por las publicaciones españolas (semanarios y el Diario de los literatos) y, sobre todo, justificaba su decisión de abandonar la Corte. Sus esfuerzos por educar a los jóvenes en el estudio de las leyes y, de manera especial, su proyecto de recoger y hacer públicas las fuentes de la historia civil y eclesiástica de España, de nada le valieron y no podía llevarlos a cabo para lustre de la República Literaria. En consecuencia, se retiró a la casa paterna, donde quizá no pueda perfeccionar sus proyectos, pero al menos no gastará la hacienda familiar, como ocurría en Madrid. No crea Muratori, añadía, que piense llevar una vida ociosa en Oliva. Ya ha emprendido dos obras: una sobre la edad de Cristo y otra la Razonatoria. Ambas permanecen inéditas, y quizás la segunda vea pronto la luz pública. Según decía Mayans a Muratori, se trata de un tratado sobre el uso de la razón, en una síntesis de teología, filosofía y artes liberales, en cuya redacción pensaba utilizar los libros del bibliotecario de Modena, en especial la Filosofía moral y De ingeniorum moderatione (19-VIII-1740).

Con ello entramos en el influjo de Muratori en el pensamiento religioso de Mayans, hoy bien conocido. Educado en un colegio de jesuitas (Cordelles, Barcelona) y en el seno de una familia muy religiosa con muchos miembros clérigos y monjas, el erudito de Oliva sufrió una evolución espiritual muy interesante. Descubrió y leyó con pasión los autores del humanismo cristiano (Arias Montano, Fr. Luis de León, 
Vives o Erasmo) que unían piedad y letras. Pero también leyó, durante los años de bibliotecario real, las obras de Van Espen con su regalismo con tintes jansenistas cuya lectura aconsejó a eclesiásticos y juristas seglares. Conoció, además, el regalismo galicano con los grandes tratadistas religiosos del siglo XVII francés (Bossuet, Fleury, Mabillon...). Sin olvidar, por supuesto, la naciente filosofía moderna, expresada por Descartes, Gassendi o Locke, ni los jusnaturalistas, de Grocio a Pufendorf y Heinecio.

En consecuencia, resulta coherente su actitud de humanista cristiano que acepta la armonía entre razón y revelación, razón y fe, porque ambos campos (natural y sobrenatural) tienen el mismo origen en Dios. Por eso, si Mayans acepta los presupuestos básicos de los jusnaturalistas (aunque rechace la herejía protestante en los criterios concretos de algunos juristas), tenía que ver con simpatía los planteamientos intelectuales de Muratori, tanto en su crítica del escepticismo como en su censura de la superstición. Las manifestaciones de esta actitud receptiva son múltiples.

La lectura del De ingeniorum moderatione, que leyó por iniciativa propia, le hizo conocer los presupuestos intelectuales de equilibrio entre racionalismo y superstición. Por eso, al recibir De superstitione vitanda, y antes de iniciar su lectura, manifestó su juicio sobre la crítica muratoriana del voto sanguinario. Se trataba del voto, emitido por muchos católicos especialmente españoles, de derramar su sangre en defensa de la Inmaculada Concepción de la Virgen María. Como en esas fechas no era todavía un dogma definido por la Iglesia Católica, Muratori pensaba que ese voto era un acto supersticioso.

El criterio de Muratori fue combatido en Italia y, por tanto, era lógico el recelo que manifestó al enviar De superstitione vitanda al valenciano: «Unus fortassis eris qui in Hispania copiam eiusdem sis habiturus, neque enim audebit inter vos versari liber». El erudito italiano sabía cuán apasionados eran los españoles en defender el voto sanguinario $\mathrm{y}$, aunque no faltarían varones doctos que apoyasen su criterio (como muchos teólogos lo aceptaron en Roma), suponía que recibiría «spicula et dicteria» (8-II-1741). El recelo de Muratori estaba fundado y ya expuse en 1972 algunos ejemplos. Y los Mayans eran conscientes. Por eso, cuando, a la muerte de Muratori, su sobrino Gian Francesco Soli pidió la copia de la correspondencia, Juan Antonio Mayans dejó de transcribir esas palabras sobre el voto sanguinario.

Pues bien, aun antes de leer De superstitione vitanda, Mayans dedujo la actitud de Muratori por los principios expuestos en De ingeniorum moderatione, y con serenidad expresó su criterio personal. Dada la devoción a la Inmaculada, familiar y personal, pensaba que la Virgen está contenta con la defensa de las prerrogativas ciertas y reveladas que exigen la fe y la defensa, si fuere necesaria, con la vida. Pero consideraba que convenía presuponer las verdades reveladas «ex quibus necessario alia colligantur atque credenda». Dicho de otro modo: no veía claro cómo se podía deducir la Inmaculada Concepción de otras verdades ciertas «fide divina». Ahora bien, don Gregorio había publicado en plena juventud una oración sobre La Concepción puríssima de la Virgen María Madre de Dios (1728), y los presupuestos intelectuales de Muratori le plantearon más de un problema. En correspondencia posterior, don Gregorio manifestó sus dudas. Así en carta al clérigo sevillano Jose Cevallos, escribía: «Yo a nadie cedo en la devoción a la Concepción de la Madre de Dios. Pero de la dificultad que hay para que se defina como misterio de fe, no puedo salir, porque 
se me presenta al entendimiento que, para que se defina, es necesario que las premisas de que se infiera esta conclusión sean reveladas (pues se habla de un misterio) y no las hallo tales en las Divinas Escrituras» ${ }^{12}$.

Mayans tenía una concepción estática del dogma católico. Por eso comenta que no había encontrado esa verdad en los teólogos antiguos, ni en los mayores modernos (Arias Montano, Antonio Agustín y Bossuet) y, en consecuencia, no ve con claridad que haya una Tradición del misterio. Por eso, ante la insistencia de Cevallos para que el valenciano declarase su pensamiento sobre la definibilidad de la Concepción, escribirá: «Los hombres son los que hacen los silogismos y sacan las conclusiones científicas y de fe. Pero las premisas y las conclusiones ya son antecedentemente de fe. No puede haber proposición de fe que no conste de la divina Escritura o de la legítima Tradición; y si consta de la Tradición después debe haberse escrito para que nos conste la Tradición antecedente. Las proposiciones de fe, unas son expresas, otras inferidas de premisas de fe. Tan de fe es la inferida como la inferible, porque Vm. que infiere no lo hace de fe infiriéndola, sino que conoce que es de fe... Si el misterio de la Concepción estuviera claro en las divinas Escrituras, sería de fe, y herejía negarla. Si en algún tiempo se hubiera de definir, ya seria hoy de fe, como lo era la procesión del Espiritu Santo antes que se declarase de fe». Y, como Cevallos le había escrito de forma absoluta: «De ahí se infiere que la Concepción se definirá, o es próximamente definible, porque se infiere con certeza teológica de premisas de fe», el erudito evitó mayores discusiones sobre si «es definible el misterio de la Concepción» ${ }^{13}$.

Sin embargo, don Gregorio no quedó satisfecho, pues sentía una disonancia entre su piedad y sus planteameintos racionales. En fecha ya muy tardía se haría eco de los planteamientos de Muratori, en carta al obispo de Beja Fr. Manuel Cenáculo de Villas Boas: «I assí vea V.S.Ilma. cuánto devo estimar su Disertación Teológica, histórica, crítica, sobre la definibilidad del misterio de la Concepción Inmaculada de María Santíssima. Yo la creo en el último grado de la creencia humana. Pero desde que lei a Muratori De superstitione vitanda, se me clavó en el corazón una espina que me causa mucho dolor, i quiero ver si, para arrancarla $i$ esperar que llegará el tiempo de esta deseada definición de la Iglesia Cathólica, será buen remedio la lectura del libro de V.S.Ilma» ${ }^{14}$.

He puesto un ejemplo del profundo influjo que la lectura de las obras de Muratori ejerció en el pensamiento religioso de Mayans. Y, por supuesto, no es el único. Me limitaré a insinuar otros puntos conocidos.

En 1746 la Filosofia morale de Muratori fue delatada a la Inquisición valenciana. Apenas lo supo Mayans, se apresuró a escribir al Nuncio en Madrid Mons. Enrico Enriquez, para evitar la prohibición o condena de «una Filosofía moral, que casi podemos decir que es la única que no tiene resabios de gentilismos i que está escrita con espíritu verdaderamente cathólico, por no conformarse con la opinión de algu-

12. Mayans a Cevallos, 25-IV-1750. Texto en A. MESTRE, Correspondencia de los ilustrados andaluces, Sevilla 1990, p. 134.

13. Cevallos a Mayans, 14-VII-1750 y Mayans a Cevallos, 8-VIII-1750, en Ibíd.

14. Mayans a Villas Boas, 15-VIII-1772. Texto en a. MESTRE, Ilustración y reforma de la Iglesia... p. 344-345. 
nos escotistas, incurriesse en una nota ignominiosa» ${ }^{15}$. La intervención del Nuncio paralizó el proceso contra la obra de Muratori, que quedó libre de toda mancha.

Por lo demás, en la correspondencia mayansiana pueden espigarse numerosos testimonios en que el erudito de Oliva alaba calurosamente los libros más renovadores de Muratori. Valga un ejemplo que abarca las dos obras de que venimos hablando: «La Iglesia Cathólica sólo reconoce por revelaciones verdaderas las que nos vienen continuadas por una legítima Tradición y por las Escrituras canónicas. Desto, como de muchas cosas, trata excelentemente Luis Antonio Muratori en el libro De ingeniorum moderatione $i$ en el De vitanda superstitione, impresso el primero en nombre de Lamindo Pritanio, $i$ el segundo en nombre de Antonio Lampridio, anagrama del otro. Pero porque lo trata bien se prohibirá» ${ }^{16}$.

Mayans acertó a medias. De ingeniorum moderatione, pese a que planteaba los principios filosófico-teológicos, no sufrió dificultad alguna, y fue utilizado por Mayans -también por Burriel- para defender la teoría heliocéntrica de Jorge Juan y Antonio Ulloa ante el Inquisidor general Francisco Pérez Prado. Pero De superstitione vitanda no fue tan afortunado y desde el primer momento, provocó suspicacias. Emile Appolis estudió con minuciosidad las reacciones en Europa ante esta última obra muratoriana ${ }^{17}$, y yo indiqué en 1972 algunos casos españoles. Baste saber que personalidades como el jesuita Burriel o Asensio Sales, catedrático de teología en Valencia y después obispo de Barcelona, manifestaron sus recelos ${ }^{18}$. De hecho, pese a los elogios de Mayans y su amistad con el Fiscal de la Suprema Agustín Orobio Bazterra, no pudo evitar que el santo Oficio prohibiera De superstitione vitanda, después de la muerte de Muratori. Las lamentaciones de don Gregorio fueron frecuentes: «Muchas veces avia dicho yo que, quando muriera Muratori, le prohibirian algunas obras. Assí ha sucedido en su libro De superstitione vitanda. I sucederá lo mismo en otras del mismo autor, a quien, mientras ha vivido, he tenido $i$ respetado por el cathólico más sabio de nuestro siglo». Y en otra ocasión dice explícitamente: "Leí con gusto el librito de Muratori i con disgusto la prohibición de su obra De superstitione vitanda».

Aunque, a decir verdad, la prohibición inquisitorial no disminuía, a los ojos de Mayans, el valor de las obras de Muratori pues, como recordaba en carta al Fiscal de la Suprema Orobio Bazterra, comentando la prohibición De superstitione vitanda, todas las decisiones del santo Oficio están expuestas al juicio «de la posteridad $i$ de los hombres críticos, pues hoi corren los libros del Maestro Avila, que en otro tiempo se prohibieron, $i$ otros muchos» (11-VII-1750). Desde esa perspectiva se comprende que los partidarios de una religiosidad más tradicional, al traducir Della regolata divozione de' cristiani, omitieran las palabras de Muratori favorables a la disminución del número de fiestas de precepto -asunto que provocó agrias polémicas en Italia- así como la explicación de la misa con el texto en lengua vulgar de la misa de un domingo del año. Pero también resulta coherente que don Gregorio defendiera la actitud reformista de Muratori y tildara de supersticiosos (entre ellos al P. Flórez) a quienes habían impedido la traducción íntegra del texto muratoriano ${ }^{19}$.

15. Mayans a E. Enriquez, 12-VII-1746, BAHM, 140.

16. Mayans a Agustín Sales, 21-X-1741, BAHM, 130.

17. E. APPOLIS, Entre Jansenistes et Zelanti, le «Tiers Parti» catholique au XVIII siècle, Paris 1960

18. A. MESTRE, Muratori y la cultura española, p. 197 y 201.

19. Ibíd., 208-209. 
El camino estaba abierto y las traducciones de Muratori al castellano se sucedieron. En general se trataba de los libros reformistas, porque Rerum italicarum scriptores fue utilizado por los historiadores, especialmente por Capmany, y fueron bien acogidos por los lectores españoles. Y la actitud de Mayans contribuyó positivamente a la buena acogida que se tributó al pensamiento del erudito italiano. Quizás el lector quede sorprendido de que a una correspondencia, que sólo consta de 9 cartas escritas entre 1739 y 1743 , se le atribuya tanta importancia. Pero no se le puede negar. En España todos sabían la amistad de Mayans con Muratori y compraron y leyeron los libros del italiano con interés. Me limito a indicar unos pocos lectores: clérigos (Burriel, Cabrera, Agustín y Asensio Sales), juristas (Bermúdez, Borrull), inquisidores (Andrés I. Orbe, Orobio Bazterra). No hay duda de que Muratori tuvo adversarios, pero la oposición fue mucho menor de la esperada, debido, en gran parte, al influjo de don Gregorio. Así lo confiesa un conocedor tan profundo, tanto del pensamiento italiano como del español, como el P. Miquel Batllori que, al señalar la diferencia entre la radical oposición a Muratori en Nápoles y la relativa buena acogida en España, explica las razones en la actitud de Mayans: «Ci fu però una diferenza, che cioè mentre in Napoli la polemica antimuratoriana giunse alle stridenti invettive di padre Pepe, in Spagna la lotta non fu violenta -senza dubbio perché l'influsso del Muratori vi fu meno sentito, diffuso piuttosto nell'ambiente dei laici rinnovatori della coscienza religiosa e civile, quale fu Gregori Mayans $i$ Siscar e i suoi innumerevoli amici e seguaci, forse piú numerosi che $i$ suoi accaniti nemici» ${ }^{20}$.

\section{L. A. MURATORI A G. MAYANS, 10 DE MARZO DE 1739}

Clarissimo viro Gregorio Maiansio, Catholici Regis Bibliothecae praefecto, Ludovicus Antonius Muratorius S. P.

Teneo libros tuos, humanissime Maiansi, et eos quidem mihi perquam caros, sed longe cariores, quod illos volueris tui erga me amoris testes. Obstupui sane, eo felicitatem meam processisse, ut in tam dissito a nobis regno amicum habere et qualem quaeso? Omnigenâ scilicet eruditione ornatum et in amplissimo literarum emporio situm. Itaque vix libris tuis mihi traditis, calamum arripui ut tibi statim significarem quanta tibi debeam et quanti beneficia tua tuumque amorem ego faciam. Ubi a bibliopego libros eosdem recipiam, lubentissime legam. Argumenta tantummodo perspexi atque cursim plagulas aliquot percurri. Habeo quod tibi gratuler ac praesertim ob $\mathrm{Vi}$ tas Antonii Augustini, magni viri, ac lepidissimi Cervantes. Vestrum dumtaxat erat illustrium horum virorum facta colligere. Gratissimum quoque mihi erit accipere quid de Origine hispanicae linguae fueris commentatus. Inter meas Antiquitates italicas medii aevi, quorum tomus I in folio iam prodiit, reliqui tres brevi prodibunt, erit et Dissertatio de origine linguae italicae. Utinam et tuam antea legissem mihique datum fuisset te advocare in eiusmodi parem provinciam. Sed quandoquidem sub praelo quoque est alterum opus meum, nempe Thesaurus novus veterum inscriptionum, duobus aut tribus tomis in folio constans, illuc inferam paucas i(n)scriptiones illas, quas e libris tuis excerpsi a Grutero, Reinesio, Fabretto et Sponio praetermissas, tuique nominis honorificam mentionem faciam.

20. M. BATLLORI, Cultura e finanze. Studi sulla storia dei gesuiti da S. Ignazio al Vaticano II, Roma 1983. 
Linguae latinae elegantiam miratus sum in vestrate Martino. In hocce ornamento ne tu quidem alicui concedis; vadem habeos literas tuas, quas cum voluptate propediem legam. Sed quod potissimum iam in te deprehendisse mihi videor, aeruginem a te excussisti, qua (sit verbo venia) apud nos hispanica ingenia teneri creduntur. Quam acuta sint sub vestro caelo ingenia, quam apta ad omnes disciplinas, ego quoque libenter agnovi in libro, quem sub nomine Lamindi Pritanii olim evulgavi, et cui titulus est Del buon gusto nelle arti e nelle scienze. Attamen rarus fertur apud vos critices usus et antiquis tabulis ac praeiudiciis adhuc vos distineri audio. Ea fortassis invaluit opinio, quod paucos aut nullos e libris vestris Italia accipiat. Tu certe prodis, quam longe a literatorum vulgo abeas tum dextritate ingenii, tum solida eruditione et elegantiâ stili. Egregie quoque doctum novi marchionem Sanctae Crucis, amicum olim meum, quem Africa nobis eripuit, in libris de militia. Si versari ego possem inter manuscriptos codices Escurialis, occurreret, ut spero, mihi, unde uberius de Republica Literaria bene mereri pergerem. Est fortasse tibi collectio mea Scriptorum rerum italicarum ab anno 500 ad 1500, quae XXVII tomos in folio complectitur. Vide quot et quanta e tenebris eduxerim. Tibi autem sum, ut quum tanta tibi sit eruditionis supellex, codices etiam manuscriptos in publicam utilitatem convertas.

Ceterum, si qua tibi vetus inscriptio occurrat, quae in maioribus collectionibus hactenus desideretur, etiam atque etiam te rogo, ut excerpas atque ad me deferendam cures. Neque enim, uti arbitror, ante finem currentis anni Thesauri mei editio absoluta fuerit. Hac ratione crebrior mihi occasio erit ingerendi nominis tui in italorum oculos. Contra, si quid et ego praestare possum tuis utile studiis, noveris me perlibenter facturum quaecumque indicaveris. Demum quod super omnia rogatum te volo, amare me perge, numquam interituri amoris me iam certus. Vale. Mutinae VI Idus Martias MDCCXXXIX.

\section{G. MAYANS A L. A. MURATORI, 13 DE ABRIL DE 1739}

Clarissimo et sapientissimo viro Ludovico Antonio Muratorio, Mutinensis Ducis Bibliothecae praefecto, Gregorius Maiansius, S. D.

Septimus annus hic est, ex quo captus ego novitate libelli tui De bono gustu in artibus et scientiis, cupidus cognoscendi quid in tam utili argumento scriptum esset, coepi eum legere, tantumque mihi placuerunt quae ibi docuisti, ut vix ullus sit ex amicis meis qui, me invitante, non illum legerit. Ex eo tempore avide arripui scripta tua quaecumque in manus meas inciderunt: De peste, De caritate christiana, De philosophia morali, quam bona ex parte converti in hispanam linguam, et libenter eam publicassem, nisi veluti pestilenti quadam contagione nostratum ingenia ita essent corrupta, ut eis sanandis libri non sufficiant, sed una Dei providentia. Nam, si sanitatis principium est velle sanari, quid facies illis qui, cum aegri sunt, medicamenta respuunt, et animorum medicos insanire putant? Nam desunt, mihi crede, inter hos abderitas Democriti aliqui. Deest Hippocrates fama clarus, cui fidem illi adhibere velint. Uno verbo, deest praemium et honor ille qui benemeritis redditus, alit artes. Si quis paulo altius velit caput attollere, statim omnium oculi in eum intenti, non admirandi, sed vituperandi et deprimendi caussa. Vel unus Marchio Sanctae Crucis, amicus olim tuus, exemplo sit qui, cum esset regi carus, Reipublicae utilis et aliquando tinctus colore literarum, maxima invidia laboravit, donec a mauris ob nimiam animi ardorem 
occissus fuit. Sed quid exemplis opus est? Certe ego, si non ea imbutus literarum cognitione, quae necessaria est ad reparandas scientias (quod ultro fateor) at saltem habeo indicem quo (vel si mutus essem) designare possem veram viam ad sapientiam. Orationes scripsi, et scripta edidi, quibus hispanos exhortatus fui, ut doctrinae fontes adirent, vetera monumenta perquirerent, ob oculos versarent, mente agitarent, utque, preiudiciis omnibus abiectis, in singulis artibus et scientiis, eos tantum imitarentur qui omnium hominum consensus, digni sunt imitatione. Scire cupis quos ego fructus ceperim? Valentiae, ubi Iustinianeum Codicem per decem annos enarravi, repulsam primum, deinde cathedrae, honoris caussa mihi antea propterea quod creatus essem bibliothecarius regius, illius civitatis spontaneo decreto conservatae expoliationem iniustam, quam aequo animo tuli, etsi ulcisci possem supplici libello regio oblato. Sed quid facerem? In patriam domumque meam redire cogitans, Madridi ineptissimorum hominum satyras et aliorum morionum irrisionem pertuli non aliam ob caussam nisi quia illis essem dissimillimus studiis et factis. Quid consilii et operum omni favore destitutus? Adolescentulus cum essem, animum intendi ad illustrandum Ius Civile Romanorum. Aliqua dedi documenta conatus mei. Nemo promovit illum. Consilium illud seposui. Postea mentem applicui ad faciendam collectionem aliquam monumentorum pertinentium ad Hispaniae illustrationem. Solum optabam unius preli typographici dotationem modicam. In alia omnia itum. Qui haec, et alia, optimo et erudito regi privatim proponeret, licet ea ego publice dixerim, inveni neminem. Praetera dixi editurum me sapientissimorum hispanorum scripta quam plurima in hac regia bibliotheca et in scorialensi latentia, quibus Hispaniae res mirum in modum illustrarentur, et nominatim designavi Nicolai Antonii octo volumina praegrandia pertinaci labore a me descripta, quibus impostorum fabulae mirum in modum profligantur, nec magis auditus sum, quam si loquerer rebus natura surdis et omni sensu carentibus. Verum omnia haec mirari desine. Audi rem prope incredibilem. Non solum antiquis fabulis ac praeiudiciis distinentur adhuc nostratum ingenia, sed mentes animosque accomodant impostoribus novis, eorumque turpissima mendacia turpius probant. Superiore anno in hac urbe regia, in regiae bibliothecae domo (sed rege inscio) typographicis formis excutus fuit libellus, in quo antiqui Hispaniae reges, hi omnium primi recensentur, Tharsis, Heber, Neptunus, Gadiricus, Athlas, Hercules, quorum successores ad Philocorum usque, qui aerae christiane anno 44 vixisse fingitur, argumentum erunt sex librorum sequentium, et horum postremus continebit Petri Oratoris Chronicon. Frontem contrahis? Rogatus ego sententiam ab Regio Castellae senatu, dixi illius chronici auctorem fuisse Iosephum Pellicerium, addidi autographum esse in regia bibliotheca, argumentis luce meridiana clarioribus probavi chronicon illud contrarium esse sacris literis, omni mythologiae, omnium gentium historiis. Tamen chronici illius commentariolus mendaciis refertus in lucem prodiit, sententia mea despecta, prelataque illorum qui librum ipsum probaverunt, adeo ut iidem rei ac iudices fuerint. Praeterea duae Academiae Regiae, Linguae scilicet Hispanicae et Historiae, ante meam et post meam sententiam, eadem illa mendacia comprobarunt, et elegerunt homines qui typographiarum iudicem adirent et academiarum nomine ab eo peterunt ut permiteret librum in lucem edi, sententia mea superhabita, quae, ut ipsi aiebant, praevalere non debebat Academiis obsistentibus. Ipse cardinalis Molina, Regii Castellae Senatus Gubernator, a me per schedulam admonitus de libelli imposturis, tamen auctoritatem suam ei praestitit, et regi sapientissimo ausus est offerre anathema illud. I nunc, anti- 
qua rudera lustra, inscriptiones erue, onera te pulvere, et in ipsa, si placet, monumenta conde te cum istis antiquitatis reliquiis, donec alii homines nascantur et alia sint feliciora tempora, quibus haec praestare in pretio sit. Cum videam igitur me nihil eorum quae cogitaveram efficere posse, statui secedere in patriam meam Olivam, atque ibi, volente Deo, philosophiae vacare. Eo misi bibliothecam meam et cum ea manuscripta unde inscriptiones aliquas ineditas tibi possem describere, quod libenter faciam quam primum illuc pervenero. Vellem ut hispanienses inscriptiones in volumen ultimum reservarentur, si operis abs te instituti ratio id permittit. Atque scire cupio quibus libris usus es ad collectionem hanc adornandam. Lusitaniae quam plurimas inscriptiones habes apud Andream Resendium, antiquarienses, apud ludimagistrum nescio quem in Supplemento Salengriano; valentinas, apud Petrum Antonium Beuterum, Gasparem Escolanum, Franciscum Diagum et Iosephum Vincentium del Olmo; tarraconenses, apud Ludovicum Ponsium Icartium et Antonium Augustinum; barcinonenses, apud eundem Antonium Augustinum; totius Principatus Cataloniae, apud Hieronimum Puiadesium et Petrum de Marca; conventus iuridici Hispalensis, apud Rodericum Carum; cordubenses, apud Petrum Diaz de Ribas; gaditanas, apud Iohannem Baptistam Suarezium et Hieronimum a Conceptione; granatenses, apud Ferdinandum de Mendoza et Franciscum Bermudezium de Pedraza; alias aliorum locorum, apud varios scriptores, praecipue Ambrosium Moralem, a quo suas descripsit Adolphus Occo. Quamquam non paucae eorum spuriae sunt et aliae quam plurimae emendatius edi debent. Operae pretium feceris, si e bibliotheca barberina tibi curares describi vetera aliqua Hispaniae monumenta seu lapides et inscriptiones quas Ioannes Baptista Valenzuela Velasquezius, episcopus salmanticensis, obtulit olim cardinali Francisco Barberino, cum in Hispaniam venit, Urbani VIII de latere legatus, quasque in eius bibliotheca manuscripta vidit Nicolaus Antonius. Si ad alium scriberem, diligenter admonerem non esse facile fidem adhibendam inscriptionum descriptoribus, si Antonium Augustinum et paucos alios excipias. Nam cum plerique ad manum non haberent inscriptiones, quas impostor ille Cyriacus Anconitanus confixit, dum alios describerent, incaute in easdem inciderunt. Apud Gruterum igitur aliosque multae inscriptiones leguntur inter non suspectos, quae procul dubio inter spurias esse deberent. Exemplo sint celebres illae inscriptiones de christianorum persequutione in Hispania Neronis et Diocletiani temporibus, quas nemo vidit, et tamen a viris eruditissimis ut extantes allegantur. Taceo ipsas per se prodere falsitatem suam quam perfacile est manifestare. Spero te haec et alia, quae diligentiam et iudicium tuum desiderant, praestaturum. Et, si levi manu aliqua adnotare me iusseris, indicabo nonnulla scitu digna. Interea accipe paucas istas inscriptiones, plures a me accepturus ubi primum ex te sciam ex quibus libris quas hucusque collegisti, excerpseris, ne bene actum, male aut ociose agam. Illustrissimum virum Guidonem Eustachium Lucarellum, cui ego debeo amicitiam tuam, meo nomine saluta. Et, si de me recte iudicare vis, cave existimes aliquem esse in orbe terrarum qui te sanctius colat. Madridi Eidibus Aprilis an. 1739.

- Olauri, hodie Lora. Ex epistola eruditissimi viri Martini Vasquez Siruela, oculatis testis.

I.MODIVS.C.F.

...VS.OLAV

RENSIS.A.V. 


\section{XXXX.PIVS.IN}

SVIS.H.S.E.S.T.T.L. ${ }^{21}$

- Alamedae prope Rodam in Baetica. Ex eadem epistola

...HERCVL

....IMIGENIVM ${ }^{22}$

Pertinet haec inscriptio ad Herculem Primigenium, de quo Gruterus, pag. CCCXV, num. 2.

- Ibidem in fragmento marmoris. Ex eadem epistola.

..AVS.ASTIGIT

OR.D.D. ${ }^{23}$

- Acci, hodie Guadix in horto. Ex epistola eruditissimi viri Thomae de Leon, societatis Iesu, ad Casparem Ivañez de Segovia marchionem Acropolitanum.

LIVIA CHALCEDONICA

ISIDI DEAE D.

H.S.E.

ORNATA VT POTVIT

IN COLLO H MONILE

GEMMEVM. IN DIGITIS

SMARAGD. XX. DEXTRV. ${ }^{24}$

- Oscae, hodie Huesca, in ecclesia S. Vincentii Alti. Ex schedis Hieronimi Suritae. Apud Franciscum Andream Ustarrozium in Museo Manuscripto emendatius quam in Gruterum, p. CIV, n. 1.

L.CORNELIVS PHOEBVS

L. SERGIVS QUINTILIVS

SEVIRI. AVG.

D.S.P.F.C. ${ }^{25}$

- In tabula eburnea reperta in agro Gerundensi. Apud Franciscum Pacciecum, in Antiquitatibus et praerogativis picturae, pag. 612 .

HE SVNT RELIQVIAE

SCI. ROMANI .T SCI

TOME MARTIRVM QVI

APVT GERUNDAM

CLAVIBVS TRASFIXI

MARTIRIVM PASSI

SVNT $^{26}$

21. AEMILIUS HÜBNER, Inscriptiones Hispaniae Latinae, n. 1448.

22. Ibíd., n. 1436.

23. Ibíd., n. 1443.

24. Ibíd., n. 3.387.

25. Ibíd., n. 3.002.

26. AE. HÜBNER, Inscriptiones Hispaniae christianae, Berlin 1871, n. 102. 
- Tarracone in propugnaculo. Ex Hieronimi Suritae Cantabria, pag. 29. Consule Gruterum, pag. CCCCXXIV, num. 10.

PAETINIAE MA

TERNAE PATERNI

FIL. AMOCENSI CLVNIENS.

EX GENTE CANTABRO.

FLAMIN. C.P.H.C.L.AN

TONIVS MODESTVS

INTER CAT.EX GENTE

VACCAFOR. VXORI. PI

ENTISS. CONSENT. QN. CS. Q. F. ${ }^{27}$

- In Turri Portus Brigantium, nunc La Coruña, apud Alvarum Gomezium De rebus Francisci Ximenni, lib. III, fol. 57, pag. 2

MARTI

AVG. SACR

G. SEVIVS

LVPVS

ARCHITECTVS

A.F.DANIENSIS

LVSITANUS EXUL. ${ }^{28}$

Pro EXVL repone Ex.V.P. ex Grutero, pag. LVII, n. 7.

- Talabricae in monumento marmoreo, apud Alvarum Gomecium, De rebus gestis Francisci Ximenii, lib. V, fol. 140, pag. 2.

LITORIBVS FAMVLVS DEI VIXIT ANN.

A.PLVS MINVS LXXV.REQVIEVIT IN

PACE DEI VIIII.KALENDAS IVLIAS

AERA DXXXXVIII. ${ }^{29}$

- In oppido Consuegra. Apud Iosephum Pellicerium in Lectionibus solemnibus ad opera Ludovici Gongorae, pag. 156

TAGO.S.

FLVM.PRINC PRO..

INVNDATION.ARAM

CONSABVR.ET.LAMINIT.

P.P. ${ }^{30}$

- Compluti, hodie Alcalá de Henares, in via Doctoris Leonis. Apud Pellicerium, eodem lib. pag. 185

MAGNES AMORIS

27. ID., Inscriptiones Hispaniae latinae, n. 4.233.

28. Ibíd., n. 2559.

29. ID., IHC, 44.

30. ID., IHL, n. $307^{*}$ 


\section{$\mathrm{AMOR}^{3 !}$}

- Dianii, hodie Denia. Apud eundem Pellicerium, eodem lib., p. 621. Vide

D.M.

L.GRATIO.L.F.

GAL.GLAVCO.

SEGOBRICENSI.

FLAM.P.H.C.

M.ATILIVS.FRATERNVS

AMICO.OPTIMO. ${ }^{32}$

- Lapis in via strata ab oppido Alconchel ad oppidum Cabeza del Griego in finibus Celtiberiae. Apud Ioannem Baptistam Valenzuelam in libello manuscripto monumentorum aliquot Hispaniae Veterum, quem Francisco cardinali Barberino obtulit, teste Nicolao Antonio in Adversariis manuscriptis.

MP.CAESAR.D.NERVAE

TRAIANI.F.NERVAE.N

HADRIANVS.TRAIANVS.AVG.

DACICVS.MAXIMVS.BRITAN.

NICVS.MAXIMVS:GERMANICVS

MAXIMVS.PONTF.MAXIMVS.TRIB

POTEST.II.COS.II.PP.PRAETERQVAM

QVOD.PROVINCIIS.REMISI.DECIES

NOVIES.CENTENA.MILLIA.N

SIBI.DEBITA.A.MVNDA.ET.FLVVIO

SIGILA.AD.CERTIMAM.USQVE

XX.M.P.S.RESTITVIT ${ }^{33}$

Ait Valenzuela Mundam esse hodie la Cabeza del Griego in fine Celtiberiae, et Certimam fuisse ubi hodie est Nuestra Señora de la Cuesta prope oppidum Alconchel. Ex Nicolao Antonio in Adversariis. Valenzuela opinio examinanda est.

- Inter oppida Almonacirejo et Villarejo columna sic habet, eodem Valenzuela teste, post eosdem Hadriani titulos. Ex Nicolai Antonii Adversariis.

....PONT.MAX.TRIB.

POT.IIII.IMP.III.COS.IIII

P.P.A CERTIMA.M.P.D.X.

RESTITVIT IMPENSA SVA ${ }^{34}$

- In podio prope ianuam S. Isidori del Campo. Ex Adversariis Nicolai Antonii.

C.MARCIVS APILVS

MAGISTER LARV:::

31. No aparece en Hübner, ni en R.C.KNAPP, Latin inscriptions from Central Spain. Berkeley 1992

32. HÜBNER, IHL, n. 4.220 .

33. Ibíd., n. 464*.

34. Ibíd., n. $465^{*}$. 
AVGVSTOR - ET GE...

CAESARIS - AVGVST

HIC SITVS - EST

INF - XX - INAG - P. - XX X $^{35}$

- Ibid. In pariete qui est e regione Podii. Ex Adversariis Nicolai Antonii.

BENE HABET

PERVENI VNDAS ${ }^{36}$

- In via strata a Merida Salmanticam, in oppido Carcaboso, columna circumscripta. Ex Adversariis Nicolai Antonii. Sed locus suspectus est.

IMP.CAES.

DIVI TRAIANI PAR

THICI.F.DIVI.NER.

VAE.NEPOS TRAIA

NVS.HADRIANVS

AVG.PONTIF.MAX.

TRIB.POT.V.COS

III.RESTITVIT

$\mathrm{CII}^{37}$

- Ibidem altera columna circumscripta. Ex memoratis Adversariis.

IMP.CAESAR

DIVI.NERVAE.F.DIVVS

NERVA.TRAIANVS

AVGVSTVS.GERMA

NICVS.PONTIFEX

MAXIMVS.TRIBVNI

CIA.POTESTATE.CON

SVL ITERVM.RESTITVIT

CIII ${ }^{38}$

- In oppido Caparra ad ianuam cuiusdam domus vice sedilis. Ex schedis Nicolai Antonii oculati testis.

....ESARI

C EM

.......NIS ${ }^{39}$

3. L. A. MURATORI A G. MAYANS, 25 DE JUNIO DE 1739

Clarissimo Viro Gregorio Maiansio, Catholici Regis Bibliothecae praefecto, Ludovicus Antonius Muratorius, S. P.

35. Ibíd., n. 1133 .

36. Ibíd., n. 1162 .

37. Ibíd., n. 4.658 .

38. Ibíd., n. 4659 .

39. Ibíd., n. 811. 
Iam mihi, amantissime Maiansi, agnoscendum dederas in libris tuis ingenium, eruditionem solidumque tuum in literaria re iudicium. Postremam hanc praerrogativam, ceteris praeferendam, luculentius etiam expresserunt literae tuae, ubi quae apud vos studia vigeant, et quid tu pro iis restituendis et amplificandis hactenus egeris, monitum me candide voluisti. En quo acutissima hispanicae gentis ingenia declinarunt. Quum tanta possint, adhuc tamen barbarici aevi squallorem amant, fabulis atque imposturis oblectantur et eis literarum meliorum lux, quae in tot alios populos diffusa est, nondum affulsisse videtur. Sed quid aio? Vestra quoque gens saeculo Christi XVI aeruginem excusserat celebresque viros dedit. Cur quaeso in veterem barbariem delapsa rursus est? Cum emuctae naris viro, qui vestra noverat, olim loquens dicentem audivi: gratiorem apud vos esse gentem indoctam quam doctam, quippe quae facilius regatur et in omne latus vertatur, nimis etiam obstare quaesitores fidei ne quisquam bellum inferat barbaricis opinionibus, quamquam interdum ridendis. An ita sit, tu nosti. Italicis ingeniis non tam rudes compedes iniectos ego novi. Attamen si et Hispania nunc aderet sex alios viros tam probe animatos atque ad meliora laudabili zelo imperterrite currentes, qualis es tu, bene actum de literis etiam apud vos foret. Interea dolendum est vos laborare moecenatibus, immo et typographis, qui sumtibus suis literatorum foetus in lucem proferunt. Sed fortassis eiusmodi calamitas eos tantummodo libros respicit, qui ad eruditionem spectant; quippe leguleiorum, theologorum, asceticorum volumina feliciora fato frui consueverunt. Tu tamen ne animum despondeas velim. Sibi saltem sapere non levis delectatio est. Erit etiam dies aliquando tibi tuisque consiliis propitius. Ceterum gratias tibi plurimas habeo, quod meam Philosophiam Moralem tam benevole exceperis, et hispanicae linguae tradendam mediteris. Gallice etiam, ut ad me scriptum fuit, brevi prodibit. Tuus hic labor magno mihi honori foret, plurimi enim facio iudicium tuum de reculis meis.

Iam prodiit tomus I Thesauri mei novi veterum inscriptionum. Ex his collectoribus vestrorum marmorum, quos tu mihi recenses, praeter veteres iam a Grutero laudatos, nullum teneo. Usus sum schedis manuscriptis P. Cattanei, qui multa collegit. Donius quoque, qui mihi non pauca suppeditavit, Occonem et schedas Valenzuelae viderat. Itaque, si quid forte tibi occurrat, quod nondum editum, aut Grutero ignotum arbitreris, cura quaeso ut ad me deferatur. Non levis beneficio loco erit mihi eiusmodi donum. Inter illas inscriptiones, quas ad me misisti, nonnullas deprehendi iam publici iuris factas a Grutero. Reliquae sub tuo nomine proferentur.

An Hispaniam sacram et vos habeatis nondum didici. Si forte adhuc desideraretur (quod non puto) curandum foret, ut quisquam nobile hoc opus aggrederetur. Ceterum tibi copiosa messis adsurgeret, ubi te converteres ad antiquos codices regiae bibliothecae. Graecum illius catalogum vidi. Utinam et latinum videre licuisset. Vix fieri potest, quin ibi lateant luce digna, unde utilitas literis, tibi laus accrescere posset. Atque haec ad te scripta volui, quia te plurimum amare iam coepi teque amare non amplius desinam. Vale. Mutinae VIII Kalendas Iulias MDCCXXXIX

\section{L. A. MURATORI A G. MAYANS, 26 DE MAYO DE 1740}

Clarissimo viro Gregorio Maiansio, Catholici Regis Bibliothecae praefecto, Ludovicus Antonius Muratorius P.S. 
Quantus erga me foret amor tuus, iamdiu senseram, nuper etiam evidentius intellexi, quando sponte ad me misisti libros De antiquitatibus conventus Bracaraugusta$n i$. Amantissimi hominis munus, idemque praesentibus studiis meis perquam utile, quanta hilaritate exceperim animo concipere ipsemet potes. Sitientibus quum aqua aut merum offertur, quid carius? Itaque tibi innumeras habeo gratias, doni tui memor aeternum futurus.

Alias antea egeram ob libros tuos ab eadem liberalitate tua ad me profectos. Ad te utinam literae pervenerint. Nunc autem miratus fui, ac dolui, a D. Bustanzo certior factus, te Olivae in patria tua ab aliquot mensibus versari. Regiae Bibliothecae numquid repudii libellum misisti? Suspicio oborta est, te ob stipendia ditius quam par est retardata toedio victum abscessisse. Bella gerere, nova quaerere regna nunc unum videtur negotium vestrum. Literae proinde earum cultores ex frigore et fame perire sinantur. Si ita est, sortem tuam quam maxime doleo. Nobile tibi ingenium dedit Deus, singularem tu quoque eruditionem tibi parasti, quem in usum tanta, si te eremus excepit? Eremum appellavi locum, illustrem fortasse, sed in quo locupletem bibliothecam ad grandes volatus necessariam sperare non audeo. Utinam fallar. Mihi sane gratissimum erit a te audire, qui sit praesens fortunae tuae status. Amplissimum opto ne homo ad literarum ornamentum augmentumque natus in orbis angulo latere cogatur. $\mathrm{Me}$ iam senectus arripuit eiusque incommoda sentio. Oculi potissimum male habere coeperunt. Attamen quas possum horas in nova quaepiam aedificia impendo. Sed nos criticis abundamus, qui omnia turbant. Ubique pila minantia pilis, atque haec non exigua temporum calamitas videtur mihi. Attamen ne illam quidem apud vos peregrinam, si bene memini, tu monuisti. Si rescribis, quid tibi praestare possim, edicito; neque enim erga te ingratus mori velim. Nunc Venetiis et Florentiae prodeunt Ephemerides Literatorum. Quid memoria dignum apud vos prodeat, ii nosse cupiunt. Sed nos nimium coelum dividit, accessit et bellum, cuius finem ignoramus. Ego unum prae ceteris exopto, scilicet ut me ames, aeternum mihi amandus. Vale. Mutinae VII Kalendas Iunias MDCCXL.

\section{G. MAYANS A L.A. MURATORI, 19 DE AGOSTO DE 1740}

Clarissimo Viro Ludovico Antonio Muratorio, Mutinensis Ducis Bibliothecae praefecto, Gregorius Maiansius, S.D.

Eruditissum librum tuum De ingeniorum moderatione in religionis negotio legenti mihi traditae fuerunt literae quas ad me dedisti 7 Calendas Iunias. Quanto cum gaudio eas legerim, facile intelligeres, si pro tua modestia tibi posses persuadere, in ea sententia esse me, italorum omnium quotquot vivunt, esse te sapientissimum et literariae christianaeque reipublicae bono natum, a quo in aliquo pretio haberi me, aut saltem amari perhonorificum censeo. Tamen ad te scribere vereor. Menti meae occurrunt occupationes tuae, quas interpellare, nisi te iubente, non audeo. Ideo scribere desii literis illis quas 8 Calendas Iulias superioris anni ad me misisti, quasque ego accepi beneficio amplissimi viri Iosephi Octavii Bustanzii, amici mei egregii. Curavi tamen iussis tuis parere. Itaque libros De antiquitatibus conventus Bracaraugustani, quos liberalitate excellentissimi Francisci Almeidae, canonici Ecclesiae Patriarchalis Olisiponensis, egregiis virtutibus et praeclara doctrina praediti, nactus fui, antequam in manus meas pervenirent, at te transmitti mandavi. Eos ingenti tuo operi utiles esse 
gaudeo. Quos si facultas inspiciendi fuisset mihi, fortasse aliquid scriberem quod in rem tuam esset. Nunc ne omnino vacuus ad te veniam, dicam aliquid, ut per te postea inscriptionum corpore gruteriano melius uti possimus.

Magnam diligentiam a te adhiberi velim, ut manifestentur quaenam inscriptiones primum editae fuerint a Cyriaco Anconitano, cognomento antiquario, et a Bartholomeo Amantio et Petro Apiano. Nam, ut Rudericus Zapata apud avunculum suum Antonium Augustinum, Antiquitatum dialogo XI ait, ex tot tantisque antiquis inscriptionibus quas ille (Cyriacus) attulit, nullae hodie in Hispania leguntur. In quo magnam hispanis iniuriam fecit, qui ut inscriptionum copia nationes omnes (Italia excepta) antecedamus, nullis mendaciis indigemus. Nam, ut de Segobia solum loquar (praetermissis Tarracone, Sagunto, Valentia et aliis Hispaniae celeberrimis urbibus) Didacus Colmenarius, oculatis testis et fidedignus scriptor, ait vidisse se in ea urbe inscriptiones plus quam centum. En tot igitur verarum inscriptionum millia propter paucas supposititias, in falsi suspicionem incidant, velim confici indicem, in quo Cyriaci inscriptiones ad Hispaniam pertinentes per gruterianum opus dispersae numeris designentur, ne in posterum dubitetur quaenam inscriptiones ortae sint ab impostore illo. Haec diligentia necessaria est, tum quia Cyriaci libri sive manuscripti, ut puto, sive formis excussi, rarissimi sunt, tum quia evellenda est nonnullorum opinio existimantium omnes Cyriaci inscriptiones publicatas fuisse a Bartholomeo Amantio et Petro Apiano. Unde ille nascitur error, Cyriaci non esse inscriptiones, quae apud Amantium et Apianum non reperiuntur, cum tamen sciamus Petrum Razzanum, perquam familiarem Cyriaci apud Leandrum Albertum in Italiae descriptione, pag. 234, dicere se vidisse tria grandia volumina Cyriaci manu exarata atque depicta, quarum antiquitatum partem in Germania Petrus Apianus et Bartholomaeus Amantius anno 1534 typis ediderunt. Quibus verbis designatur liber qui, cum hoc titulo in lucem prodiit: Inscriptiones sacrosanctae vetustatis, non illae quidem romanae sed totius fere orbis summo studio ac maximis impensis terra marique conquisitae, etc., Ingolstadii, in aedibus P. Apiani, anno MDXXXIII, fol. Hieronimus Paulus in Barcinone ait sex haud parva volumina (Cyriaci) ad se pervenisse. Accedit alia ratio necessitatis huius indicis, nam cum vulgatae fuerunt illae inscriptiones a Cyriaco, vel potius ab Amantio et Apiano, vel quia saeculum illud criticum non erat, vel quia fraus omnibus non innotuerat, viri alioquin docti eas descripserunt, et postea cum horum posteriorum libri omnium manibus terantur et eorum probitas spectata sit, non illi qui inscriptiones finxerunt sed qui bona fide descripserunt, allegantur. Adde nonnullorum hominum levitatem, qui ut caussae suae servirent, non modo Cyriaci imposturis fidem adhibuerunt, sed illas etiam comprobarunt; inter quos agmen ducit apud nostrates Florianus Ocampius qui, cum videret sibi obiici potest nusquam comparere inscriptionem a Cyriaco publicatam, scripsit tamen Chronici Generalis, lib. 4, cap. 37, forsan comparituram, ut multae aliae a Cyriaco editae, quas ipse Ocampius per Hispaniam discurrens suis oculis vidit. Vellem vel unam designasset. Mihi aeque falsum est Ocampium vidisse Cyriaci inscriptionum bonam partem ac Iuliani, diaconi toletani, Historiam, diversam ab alterius Iuliani historiola de coniuratione Pauli ducis Galliae Narbonensis, quam manuscriptam habeo e codice summi viri Ioannis Baptistae Perezii, episcopi segorbiensis. In quo Ocampii fidem iure merito elevant Ambrosius Morales, Chronici Generalis, lib. 13, cap. 2, et Iosephus Pellicerius in Trophaeo veritatis historiae, fol. 86. Sed et ipsius Moralis prudentiam desidero et solitum eiusdem animi candorem. Nam 
Ocampio fidem adhibens in Chronici Generalis Prologo, ait inscriptiones a Cyriaco allatas, alias exstare, alias desiderari; et, cum etiam dixisset suspectas esse et haberi quae a nemine visae fuerint, seque non allegaturum Cyriaci inscriptiones, quin auctorem ipsum produceret; tamen postea non semel nomen eius tacuit, inscriptiones $\mathrm{Cy}$ riaci in medium proferens. In quo Ambrosius Morales insolenter peccavit, cum $L$. Andreas Resendius literis ad eum Elborae XIV Calendas Aprilis datis anno 1570, sic illum prudentissime praemonuisset. Tuam in congerendis antiquis inscriptionibus diligentiam merito laudo. Nec opus esse arbitror, admonere te virum talem ut non facile alienae fidei credas, nisi tute lapidem inspexeris. Multa enim afferri solent commentitia. Multa quoque parum fideliter exscripta. Quot finxit, quisquis fuit, Cyriacus Anconitanus, dum antiquarii famam etiam ab ementitis aucupabatur? Quam perperam pleraque, ut omittam ficta, non solum Petrus Apianus et amicus meus Amantius, in libro cui inscriptiones sacrosanctae vetustatis nomen fecerunt, et si qui germanicas et austriacas ediderunt antiquitates, sed qui romanas etiam atque italicas? Eruditum non vulgariter et prope ad superstitionem usque religiosum oportet esse eum qui vetusta monumenta describit. Ergo haec regula stabilienda est. Inscriptiones, quas primum ediderunt Cyriacus Anconitanus, Bartholomaeus Amantius et Petrus Apianus, adiiciendi etiam si placet Polyphilus, somniantium Alpha, Tovianus Pontanus, Pomponius Laetus, Ioannes Camers, aliique similes impostores, enumerandae sunt inter supposititias, nisi probus aliquis cautusque vir se vidisse illas affirmet. Neque fictis illis inscriptionibus prodesse debet incaute ab aliis transcriptas esse. Nullius enim auctoritas efficere potest ut mendacium fidem mereatur. Et profecto aliquando magna iniuria conflatur eruditis viris, qui propterea quod in schedis suis, memoriae gratia descriptas habuerit inscriptiones evulgatas ab impostoribus illis, allegantur ipsi ad confirmandas eas. Quid peccavit Andreas Schottus ut saepissime tam male haberetur? Quam probus ille et quam eruditus fuerit nemo ignorat. Ab Antonio Augustino, cuius antiquitatum romanarum hispanarumque in nummis veterum Dialogos XI hispanos in latinam linguam convertit, didicerat ille impostorum nomina fraudesque. Cum autem scriptorem oporteat, non minus vera ac falsa prae oculis habere, inscriptiones tam veras quam falsas in schedas suas ille bona fide coniecerat nullo illarum examine praemisso. Inde Gruterus aliique omnes illas promiscue descripserunt primis editoribus silentio praetermissis. Quid hic dicemus? Quantalibet probitate et eruditione Schottus viguerit falsa sunt quae mendacissimis hominibus mentientibus accepit. Eorum omnium quae dixi exempla subiiciam.

Inscriptiones tertia et quarta apud Gruterum, pag. CV, descriptae dicuntur e Schotti schedis. Praetermittitur posteriorem in qua Mentesanorum fit mentio, Iaënnii repertam ut quarundam, licet falsa, fert opinio, quam reputavit Morales in Antiquitatibus, fol 72. Utrumque sit, eodem Morale referente, ignoratur ubi reperta sit inscriptio tertia, eamque et aliam in qua Mentesanorum fit mentio, a Cyriaco habuit ipse Morales, Schotto antiquior. Quod si tertia inscriptio Cyriaci est, suspecta etiam mihi et secunda, Alhamae, ut dicitur, reperta. Quin et harum inscriptionum sorores consanguineas esse puto, similis argumenti septimam et nonam, apud Gruterum, pag. CIV Quarum septima Tarracone inventa dicitur et ab Amantio et Apiano edita; nona ibidem reperta, et e Schotti schedis descripta. Verum harum inscriptionum, quae Tarracone repertae dicuntur, neque mentionem fecit Ludovicus Ponsius Icartius in libro Magnitudinum et rerum memorabilium urbis Tarraconensis, neque ante Augustinus, 
archiepiscopus tarraconensis, e cuius schedis habeo tarraconenses aliquas inscriptiones, neque quisquam alius quem sciam. Schottus autem non ait se vidisse illam, quod saepe solet admonere. Adde undecimam eiusdem paginae, quae Decursae (forsan Dertosae) in Hispania Citeriore reperta dicitur et ab Amantio et Apiano et a Clusio publicata est; itemque duodecimam, quam Sagunti extare Escolanus ait, Historiae Valentinae, lib. 4, c. 15, tantum non eamdem esse immo unam eamdem, ne si bene describatur, ut necesse sit, inscriptionum undecimam pessime descriptam, cum loco Tutelae Tiberio scribi debeat, falso Decursae sive Dertosae adscribi, ubi a nemine visa est.

Acriorem attentionem meretur celeberrima inscriptio apud Gruterum, pag. CXLIX, num 4, quae descripta dicitur ex Morale, Stradaque, adstipulantibus omnino Schotti schedis. Imposuit ea Lipsio, Panvinio, Casaubono, Relando, multisque aliis eruditissimis viris. Dicitur esse Emeritae in aedibus Ferdinandi de Carra, sive Carrera aut Herrera, ut eum nominat Gruterus, pag. 155, 227, 921. An ibi reperiatur incolae dicant. Ambrosius Morales, Chronici generalis, lib. 8, cap. 55, me docet Cyriacum edidisse inscriptionem memoratam. Quo solo nomine eius falsitas detegitur. Adde illius contextum desumtum esse ex Livio, lib. 1, cap. 8, et ex Suetonio in Augusto, cap. 22. Atque ut alia desint argumenta, ipse contextus se ipsum prodit. Augusti enim consulatus duodecimus cohaerere non potest cum tribunitia potestate decimum ab eo accepta. Quod si cum Panvinio legas consulem decimum, neque cohaerebit consolatus decimus cum pontificatu maximo. Scio me loqui cum eruditissimo viro, ideoque falsitatis caussas non affero plures. Pergamus igitur ad alia.

Inscriptio nona apud Gruterum, pag. CCXXXVIII, num. 9, descripta est ex Schotti Metellique schedis, et reperta dicitur in ruinis pagi Marchesiae in Lusitania. Marchesiam numerare debes inter locos huiusmodi fictionibus accomodatos. Morales, in Chronico Generali, lib. 9, cap. 16, ait se neque inscriptionem eam vidisse, neque audisse aliquem qui eam viderit. Rumorem tamen sequitur dicentium scribentiumque repertam fuisse in Via Argentea, quae via aeque memorabilis et propter eiusmodi inventa, ac antea Scelestinae et Montesini propter incautaciones, nisi malis esse similem illi somni portae de qua summus poeta prope finem sexti Aeneidos:

Altera candenti perfecta nitens elephanto

Sed falsa ad coelum mittunt imsomnia Manes

Addit tamen Morales alios dicere repertam Cluniae. Aldus Manutius, et eum secutus Franciscus Padilla, in Historia ecclesiastica, centuria 1, cap. 24, dicunt repertam in ruinis oppidi Maramezar. Franciscus Bivarius, in non minus erudito quam fabuloso commentario ad Dextrum, laudat eandem inscriptionem et confitetur se accipisse illam a Cyriaco Anconitano, quem errore forsan typothetarum, Cyrillum vocat, pag. 116. Idemque Bivarius, ut omnium opiniones conciliet, ait illam inscriptionem pluribus in locis poni iussam. Mirum autem est tot in locis fuisse a nullo teste idoneo virum unquam et nusquam extare. Verum esto, alicubi reperiatur. Iosepho Scaligero suspecta fuit haec inscriptio. Ego existimo omnino falsam multis de causis, quas indicavi magno amico meo Francisco Almeidae, Lusitaniae ornamento. Cupiebat ille scire num Neronis nummus, qui similem habet inscriptionem apud eruditissimum virum Emmanuelem Martinum, lib. 3, epist. 11, spurius esset? Scripsi Decani Alonensis opinione et etiam mea esse, addidique eodem vitio laborare inscriptionem hanc. In 
quo mihi facile assensit praeclarus ille antiquitatis assertor, et sententia sua idem confirmavit literis, datis ad doctissimum Almeidam, quem in meam sententiam de inscriptionis falsitate pertrahere non potui. Urgebam ego latinum non esse inculcare religionem ea significatione quam inscriptio exigit. Regerebat ille latinum esse apud Ciceronem inculcare fatum. Sexcenta huiusmodi vir doctus afferre poterat. Sed quantum interest, si attendatur quid inscriptionis auctor et quid Cicero significare voluerint? Non ego disputo de singulorum verborum latinitate, neque de mera verborum coniunctione, sed de verborum coniunctione et eorumdem simul sententia. Praeterea etsi verba argumento consonarent, scribi debuisset inculcarunt, tempore praeterito. Adde inscriptionis auctorem pessime imitatum Tacitum, Annales, lib. 15, cap. 44, unde sumsit verba illa generi humano; et praecipue Suetonium in Nerone, cap. 16, cum ait: Afflicti suppliciis christiani, genus hominum supertitionis novae ac maleficae. Si Neronis tempore inscriptus fuisset lapis, inscriptio breviter sic concepta fuisset: $O b$ provinciam latronibus et iudaeis purgatam, et proculdubio provincia nominata aut demonstrata fuisset. Quod si antiquarius uti voluisset circumloquutione, minime omisisset novam illam superstitionem maleficam esse, aut simile aliquid addidisset. Accedit Neronem non saevisse in Hispania christianos, qui eo tempore pauci erant, ut colligitur ex Passione Sanctae Leocadiae, apud Antonium Nebrissensem in opusculis, quae Sanctorale nuncupant. Non ignoro quid Orosius scripserit, lib. 7, cap. 7. Nec quomodo intelligi debeat, nunc disputando, cum tu optime id scias. Scio etiam quid Prudentius cecinerit in celeberrimo hymno in laudem decem et octo martyrum caesaraugustanorum, neque nunc vacat inquirere quomodo sit explicandum. Illud tamen omittendum non est martyrem antiquissimum omnium quos ille laudat fuisse sanctum Fructuosum episcopum tarraconensem, qui palmam adeptus est feria VI, quae fuit 12 Kalend. februarias anni Nativitatis Christi 259. Sed longis disquisitionibus praetermissis, hoc tantum dico neminem mihi vel unum eius temporis martyrem in Hispania designaturum. Quid igitur effecit persequutio neroniana?

In eumdem censum confictarum a Cyriaco inscriptionum referri debet illa apud Gruterum, pag. 247, num. 3, descripta ex Panvinio et Schotti schedis, et reperta, ut dicitur, in Hispania, in ruinis pagi Marchesiae, cum tamen eam praeter Cyriacum nemo viderit, ut indicavit Morales, Chronici Generalis, lib. IX, cap. 28. Falsitatem huius inscriptionis duxit summus vir Nicolaus Antonius in Bibliotheca Hispana Veteri, lib. 1, cap. 14.

Eamdem censuram merentur inscriptiones tertia et quarta apud Gruterum, pag. 280. Utraque Cluniae, qui locus, ut Marchesia, inscriptionibus infaustus est, reperta dicitur, et e Schotti schedis descripta. Sed, si quaeramus quis primum eas in lucem protulerit, inveniemus fuisse Cyriacum Anconitanum, testibus Ambrosio Morale, Chronici generalis, lib. 10, cap. 26, et Francisco Padilla in Historia ecclesiastica, centuria 4, cap.1. Hodie nusquam comparent. Unus Cyriacus bipedum omnium perscacissimus eas vidit, qui tamen non animadvertit Diocletianum et Maximianum, quibus Iovii et Herculi agnomina diligenter apposita, inscribi debuisse in monumento publico cum suis praenominibus nominibusque, praemisso imperatorum nomine, ut videre est in inscriptione, quam refert L. Andreas Resendius, lib. 3 De antiquitatibus Lusitaniae, et ex eo et Morale, Gruterus, p. 199, n. 4. Praeterea Cyriacus scire debuerat Dioclecianum, saevissimum christianorum hostem, deposuisse imperium XI Cal. maias, anno aerae christianae 304, perseverante christianorum persequutione eo anno 
et sequenti. Si igitur nomen christianorum iam erat deletum, ut falso ait inscriptio tertia, si superstitio christiana ubique deleta erat, ut impie ait inscriptio quarta, consequens est inscriptiones loqui de persequutione finita. Quomodo igitur vocatur Caesar Augustus Diocletianus homo privatus? Omitto alia.

E Schotti etiam schedis descripta est inscriptio 4, apud Gruterum, pag. 404, diciturque reperta ad Rhodam, ubi nemo eam vidit praeter lynceum illum Cyriacum, referente Ambrosio Morale, in Antiquitatibus, fol. 85. Huic inscriptioni perquam similis est alia quam affert Aldus Manutius minor in Orthographia Maiori, pag. 375, laudatque eam ut Tarracone exstantem, quod nescio an verum sit.

Plura eiusmodi exempla afferre possem quae tu facile congeres conferendo $\mathrm{Cy}$ riaci Anconitani et Amantii Apianique inscriptiones cum gruterianis. Verum illud omittendum non est antequam Amantius et Apianus anno 1534 ederent Inscriptiones sacrosanctae antiquitatis longe lateque propagatas fuisse inscriptiones confictas a Ioviano Pontano, Pomponio Laeto, Ioanne Camerte et Cyriaco Anconitano, multasque illarum irrepsisse in Epigrammata antiquae urbis, quae Iacobus Mazochius edidit Romae anno 1521, mense aprili. Hac observatione ductus, conferri velim inscriptiones tertiam et quartam apud Gruterum, pag. 174, quarum quarta reperta dicitur Carthagine in Hispania, Morale teste in Antiquitatibus, fol. 78. Tertia vero ad quartae similitudinem efformata, desumta est ex Manutii Ortographia, pag. 68 et ex Mazochio, qui fol. 178 ait ubi sit haec inscriptio ignorari. Suppositum iudico ab incerto auctore. Quisquis ille fuerit, haec inscriptio occasionem praebuit Hieronymo Higuerae ut sub Iuliani Petri nomine in Adversario 82 excogitaret devulgaretque mendacia impia, horribilia et exsecranda, quae acutissime detexit eruditissimus vir Nicolaus Antonius, sectione 14 Pseudo Iuliani sui, quam manu mea descriptum habeo una cum Pseudo Dextro, Pseudo Maximo et Pseudo Luitprando, operibus, mihi crede, perquam necessariis ad manifestandas et reiiciendas innumerabiles fabulas quae historiam ecclesiasticam foedissime deturpant. Denique hoc est, illud immensae molis ac forsan invidiae opus, ut appellat ipse modestissimus auctor in Bibliotheca sua. Quam invidiam libenti animo in me totam derivare sinerem, si patronus aliquis esset, cuius ope hi libri publicae lucis usura frui possent. Illud obiter moneo in memorato Iuliani Adversario, ubi scriptum est Agripam legi debere Agapen, emendante eodem eruditissimo viro.

Praeter indicem, quem dixi, velim alium a te confici, inscriptionum quae ab eruditis viris in falsi suspicionem vocatae sunt. In mentem nunc venit antiquarienses inscriptiones apud Salengrium reperiri, in quarum praefatione memini me legisse aliquid consideratione dignum. Observa quo anno renovatae dicuntur antiquarienses inscriptiones, quibus auctoribus, quibus testibus. Confer easdem inscriptiones cum gruterianis, imo et eam quae apud Gruterum, pag. 437, n. 4, et Moralem, Chronici generalis, lib. 9, cap. 38, cum illa quae legitur apud eumdem Gruterum, p. 1101, n. 6, consulto capitolino in M. Antonino philosopho, ubi de mauris Hispaniae vastantibus scripsit et operae pretium facies. Plura adderem nisi vererer nimis molestum videri. Malo igitur te ipsum loqui tecum quam nostra legere.

Libri qui in Hispania prodeunt vix sunt memorabiles. Eorum titulos referre solent narratiunculae illae quae singulis septimanis evulgantur de rebus publicis, itemque Diarium Literatorum et Mercurius literarius, quos ego libros vicariis lectoribus mandare soleo. 
Scire cupis num secessum cogitarim; scito serio et obfirmato animo abdidisse me in patriam meam, posteaquam usu magistro didici, nihil mihi profuisse in Valentina Academia cupidam legum iuventutem per decem annos informasse, et in Bibliotheca Regia maximo labore per sex alios incubuisse inquirendis et colligendis insignium virorum manumentis, quorum immortalibus scriptis maxima lux accedere posset Hispaniae rebus, praesertim ecclesiasticis. Itaque, cum et scripta nostra ad Ius civile pertinentia, elaborata frustra, et aliorum manuscripta, inani labore a me collecta viderentur, nec spes ulla esset benemerendi de Republica Literaria (qua una cogitatione permotus in regiam urbem migraveram) hominibus nihili valere iussis, veni domum paternam ubi, etsi conatus meos perficere non potero, saltem non obsumam rem familiarem, quod necesse erat Madridii, ubi honorarium viginti quinque unciarum auri sufficiens erat ad infimae sortis hominem alendum, non autem ad ingenuum, Reipublicae utilia cogitantem. Ne tamen tibi videar otiose agere vitam in patria mea, duo inter alia cogito: Iesu Christi videlicet aetatem demonstrare, et Artem Rationatricem scribere. Quorum alterum mihi videor assecutus, Usserii, Pagii aliorumque magnae famae eruditorum opinionibus infirmatis. In altero quid coner dicam. In adversaria mea congessi plurima scitu dignissima. Ea nisi in aliqua opera deriventur, frustra per omnem vitam laborasse videtur. In mentem igitur venit, commode quamplurima transferri posse in artem utendi ratione, quam rationatricem voco quae, cum scientias omnes complectatur, tam late patet, quam ingenium humanum. Coeptum hoc, viribus meis maius. Quod potero pro virili praestabo. Theologiam cum philosophia et liberalibus artibus coniungere opto, et in unam veluti harmoniam redigere. Uno verbo, sapientis christiani ideam proponere molior. Scripta tua praesertim liber de Philosophia morali et De ingeniorum moderatione, magna mihi adiumenta erunt. Definitionibus, axiomatis et, ubi opus erit, exemplis ars nostra constabit.

Oculos tibi opto esse meliusculos. Si quid ad ea quae paras, mea diligentia opus est, nihil existimes tam difficile atque laboriosum, quod non pro te mihi susceptum, iucundum sit futurum. In quo, ut desint vires, probabis tamen voluntatem meam. Tu fac ut valeas, et ut in bene de humano genere merendo te ipsum vincas. Olivae XIII Cal. Septembreis an. MDCCXL.

\section{L. A. MURATORI A G. MAYANS, 8 DE FEBRERO 1741}

\section{Clarissimo viro Gregorio Maiansio Ludovicus Antonius Muratorius S.P.}

Fecit hactenus adversa mea valetudo, ut ad te scribere volentem vires deficerent, oculis praecipue ex iam familiari vitio laborantibus. Nunc quando melius habeo, calamum arripio. Redditae mihi iamdiu literae tuae fuerunt, honestissimi Bustantii ope. Completabantur illae iustam paene dissertationem de antiquis Hispaniarum inscriptionibus, quam multa cum voluptate legi. Erit illa mihi ante oculos, si quando indicem generalem Gruteri aliorumque collectorum, quem meditor, construendum suscipiam. Ibi opportunus erit locus epistolae tuae. Nolim Cyriaco Anconitano notam impostoris inuras. Ad manus mihi fuerunt illius schedae. Ex iis, quae ipse vidit, nihil est non germanum atque legitimum. Si marmora vestra (quod nescio) is quoque retulit, qualia ab alienis, non vero a suis oculis, acceperit, is mihi creditur scriptis commendasse. Porro tibi multum debeo, quod librum De antiquitatibus Bracaraugustanis ad me miseris, tuam liberalitatem, non meritum meum metitus. Dignus est auctor ille, cui gratulemur 
ob bonam mentem solidamque eruditionem. Erit ille mihi non levi usui in adornanda appendice Thesauri mei novi inscriptinum, cuius brevi tomus III prodibit et quartus demum claudet chorum. Sed quid ego pro tot beneficiis tibi rependam? Succurrit ad te mittere, meque missurum ad te spero per illustrissimum comitem Cassium, ad aulam Catholici Regis propediem a principe meo venturum, opusculum De superstitione vitanda sub nomine Antonii Lampridii a me editum. Unus fortassis eris qui in Hispania copiam eiusdem sis habiturus; neque enim audebit inter vos versari liber qui votum dandae vitae pro tuenda opinione piissima de Inmaculata Virginis Conceptione, prosternendum ac tollendum curat. Nametsi vel inter vos cordatos doctosque viros non deesse mihi persuadeam, qui mecum vel me tacente sentiant; novi tamen quam delicatae sint aures populi vestri, et quantum factiones apud vos pugnent pro eiusmodi argumento. Quod me solatur, vel in ipsa aeterna Urbe meliori eruditorum ac theologorum parti sententia mea probatur. Fortasse non effigiam spicula et dicteria contra sentientium; at mecum faciet, qui unius veritatis amore delectabatur. An ita compositi sint doctae gentis vestrae animi, tu videbis, et aliquando, ut spero, certiorem me facies.

Arduum opus suscepisti, nempe prodere aetatem Salvatoris nostri, quam in rem tot magnorum virorum conatum habemus, et modico quidem progressu hactenus. Si labor hic tuus tibi, ut opto, bene cedet, ingentem tibi plausum polliceor. Alia insuper, et quidem grandia, moliri te dum audio, gratulari subit homini imperterrito, quem fortuna quidem, sed non animus, deserit, quique vel sine Regali Bibliothecae Rempublicam Literariam multis sibi devincere beneficiis non desinit. De usu rationis mirum quot dici possint, tum errores hominum innumeros memorando, tum solidiora dogmata prodendo. Itaque, perge, hoc enim argumento supra ceteras Europae gentes hispanica fortasse nunc indiget.

Ad me quod attinet, iam prodiit tomus III Antiquitatum mearum Italicarum Medii Aevi, uti ut secundus Inscriptionum. Lucem quoque vidit altera pars Della antichità estensi, in qua caussam Terraviensis Ducatus pro serenissimo duci meo nervose, ut omnes aiunt, egi. Ad Annales Civiles Italiae deinde me contuli et brevi absolvendos spero. Sed me senectus iam urget atque infirma valetudine utor. Attamen, quandiu in vivis ero, meus erga te, virum optimum, virum doctissimum, amor stabit. Vale. Mutinae VI Idus Februarii MDCCXLI.

\section{G. MAYANS A L. A. MURATORI, 27 DE MAYO DE 1741}

Clarissimo viro Ludovico Antonio Muratorio, Serenissimi Duci Mutiensi a bibliotheca, Gregorius Maiansius, S. D.

Librum tuum De superstitione vitanda, quem Iosepho Octavio Bustanzo, amico nostro, tradidit illustrissimus comes Carolus Cassius, quam primum ad me mitti poterit, accipiam. Ex fundamentis quae iecisti in egregio opere De ingeniorum moderatione, facile coniicio qua ratione (quam solide) construxeris sententiam tuam de non emittendo voto sanguinario in laudem Immaculatae Conceptionis Deiparae. Idque ad te invitus scribo: sum enim, ut tota mea gens, Purissimae Conceptionis cultor, laudator et propugnator acerrimus. Sed Dei Mater christianorum pietate contenta, aliis suis praerrogativis minime dubiis et revelatione divina patefactis, summam exigit fidem et earum defensioni, si opus est, vitam nostram sibi vindicat iure suo. Mihi nunc argumentum serio consideranti in mentem venit oportere praemitti pro divina fide certas ex quibus necessario 
alia colligantur aeque credenda. Habes iudicium meum de sententia tua, quae nostratium obeliscos non efugiet. Cum opus tuum legam, multa, ut spero, me docebis.

Ducatus Ferrariensis caussam in Antiquitatibus Estensibus nervose te egisse pro Serenissimo Duci Mutinensi, multum tibi gratulor. In dies te tot egregiis monumentis Rempublicam Literariam locupletare, maxima voluptate lego.

De antiquis Hispaniarum inscriptionibus, nisi veritus fuissem iudicii tui perspicaciam, plura alia addidissem proximis literis. Nunc quoniam illae tibi non ingratae fuerunt, nonnulla scribam novitatem aliquam habentia. Singulare monumentum erat lapis collocatus in sacris aedibus Virginis del Cid in Aragoniae confinio, hispanicis incognitis literis exaratus, quam inscriptionem aliquantulum depravatam, si rite audita recordor, publicavit Caspar Escolanus, Historiae Valentinae, lib. 2, cap. 24, unde habuit Lastanosa in Museo numismatum hispanorum incognitorum, pag. 5, num. 175. Ne singularitatem miremur, Sagunti exstat, apud Franciscum Ramos, inscriptio altera scripta etiam characteribus incognitis in hunc modum ${ }^{40}$.

Cocupletave, maxima voluprate $6 g$ o.

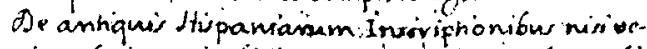
vitus fuissem juaiesi the perspicasiam, piruvaralia addicuisem proximis fiteris. Rune quoniam if lae hibi non ingratas fucvunt nonnulia scribam novitatem aliquam habentiä.

Singulave monumestum evarilapis selio catus in

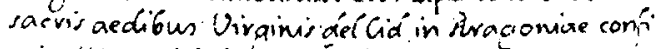

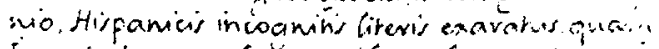
inscuiprionemaligüxasiulum áeovavaham, i! site audita recardor, publicavir Caspar. Escolanus fiskviae vaientinae fib.rt cap. 27. undeha. buit Sariancea in thuseo Humismabum tison-

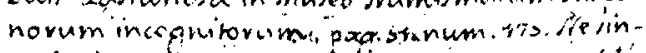

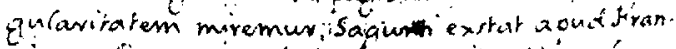

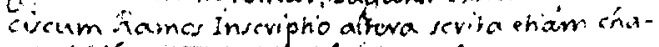
vactêvibus incoanits in hune modum:

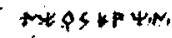

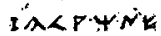

Discionus fie quikes litevis webantur Saguontini atgue have comferenaike ot coniungendae suñt cum aivi, Grevis irumismaiurn ejurdem urbis funde. sim ego ńabrol ut Saguentinovium xuicinorumque poputorum aiphabetum iniegretur, er a cietovis ishinguahir :utebantur enim Hispans, ut Shiabo coces libstrt. Gitevis. non unius gonevis. Singulis

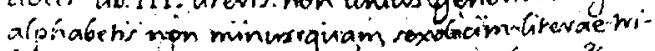
bis debent, nee plurer quam viginh duac: fiferom hes literae, quap unius: al fhabeh sumt, omnine ás dirve excluai débent fortasse inim aliguae com-

40. HÜBNER, Monumenta linguae ibericae, n. 28. 
Discimus hic quibus literis utebantur saguntini, atque hae conferendae et coniungendae sunt cum aliis literis numismatum eiusdem urbis (undecim ego habeo) ut saguntinorum vicinorumque populorum alphabetum integretur et a ceteris distinguatur: utebantur enim hispani, ut Strabo docet, lib. 3, literis non unius generis. Singulis alphabetis non minus quam sexdecim literae tribui debent, nec plures quam viginti duae. Nec omnes literae, quae unius alphabeti sunt, omnino ab altero excludi debent; fortasse enim aliquae communes erant pluribus populis praesertim vicinioribus, idque ex frequentibus literarum coniunctionibus coniiciendum est singulorum populorum numismatis observatis. Ibidem in suburbio Salvatoris, apud $\mathrm{Pe}$ trum Huarte, superest alia inscriptio quae duos ab hinc annos inter arandum reperta fuit. Ecce illam

\section{FABIA.Q.L.HIRVNDO}

AN:::......XXA ${ }^{41}$

In Fonte En Carrozii, apud aratorem in arcus pede legi nuper fragmentum inscriptionis ineditae, quae sic habet:

\section{.VFI.SER}

\section{XXXXI HS}

\section{POMPEI}

\section{GENIO}

\section{$\mathrm{HOSQE}^{42}$}

Minime dubito quin RVFI legere debeamus. In eiusdem oppidi platea exstat marmor, in quo erat celebris illa inscriptio quae legitur apud Franciscum Diagum, Annalium Valentinorum, lib. 7, cap. 31. Ex ea tantum supersunt tres aut quatuor literae. Reliquae enim attritae sunt assiduis malleorum ictibus subigendo spartum. Illud asserere audeo Diagum non descripsisse versus ordine quo scripti erant. Ad ipsum fontem, qui praedicto oppido nomen dedit, in solo supersunt vestigia alterius inscriptionis, quam eodem capite descripsit idem Diagus. Magna cum dificultate sic legitur

\section{FINIS}

\section{C.LIBERTA}

C:::IIISVM

\section{VALI $^{43}$}

In oppido Daimus, quod falso nomine Gruterus Artemisium vocat, inscriptio exstat quam male descripserunt Gruterus, pag. 903, n. 16, et Escolanus, Historia Valentinae, lib. 6, cap. 19. Errori occasionem praebuerunt literarum ductus evanidi. Brevissimam illam inscriptionem in pregrandi lapide scalis ad turrem in qua fuit collocata admotis, ego legi, atque ita habet:

\section{BAEBIAE QVI.IAI \\ EX.TESTAMENTO.SVO.}

41. ID., CIL, n. 3908.

42. Esta inscripción no aparece en Hübner, ni en J. CORELL, Las inscripciones romanas de la Safor, Madrid 1992.

43. HÜBNER, CIL, n. 3608; CORELL, n. 12 
Consule eundem Gruterum, pag. 861, n. 6, atque meo periculo sic legi:

BAEBIAE.QVIETAE

EX.TESTAMENTO.SVO ${ }^{4}$

Emendari etiam debet altera inscriptio apud Gruterum, pag. 856, n. 9, quam cum essem Valentiae ita ipse descripsi:

IM.AM

L.ANTONIVS

L.F.GA.SABNVS.E

ANTONIA.L.F.

PROCVLA ${ }^{45}$

De primo versiculo quid dicendum non liquet. Innumera alia sunt quae, apud Gruterum, emendari debent. Quin et suppleri, etiam cum profitetur se ex aliquo scriptore describere, ut pag. 256, n. 2, nam cum ibi Moralem alleget, amittit tamen inscriptionis alteram partem quam Morales representavit, lib. 9, cap. 37. Utile erit consulere in eandem rem Rudericum Carum in Relatione inscriptionum et antiquitatum Utrerae.

$\mathrm{Ne}$ Cyriaco Anconitano impostoris notam inuram a te admonitus, probare debes illum non fuisse auctorem tot inscriptionum, quas eruditi maiorum gentium asserunt eum primum evulgasse, cum nemo unquam illas viderit in Hispania, ubi repertae dicuntur. Uno exemplo contentus ero, etsi nonnulla possem adducere. Gruterus, pag. 692, num. 10, describit inscriptionem ex Morale. Repetit eandem ex Strada, pag. 694, n. 8. Morales in Antiquitatibus, fol. 86, ait se accipisse illam a Cyriaco Anconitano in Collectione inscriptionum lapidum antiquarum. Huius collectionis quisnam est auctor? Cyriacus? an Strada? autne alius? Quicumque fuerit, impostor fuit et epigramma ridiculum.

Etsi conficere indices negotium sit otiosorum hominum, no tui similium, tamen cum in huiusmodi opere a te multa expectanda sint, vel invocum emendatione et explicatione, vel in magni operis praefatione, te hortor, sapientissime Ludovice Antoni Muratori, ut laborem hunc non recuses.

Ego sum occupatus in ordinanda Nicolai Censura historiarum fabulosarum, quam proximo mense typographo tradam excudendam. Quam primum edetur hoc opus eruditissimum ad te mittam. Non deerunt seditiosi nebulones qui in me conspirent. Veritatis caussam tueor, Hispaniae veras laudes vindico, falsas contemno, sciolos despicio, tibi ac tui similibus vere piis et catholicis hominibus gratus esse cupio. Tu, si quid existimas me praestare posse, indica. Ego interea, te laudando, praedicando, supra mortales quotquot vivunt celebrando, tibi satisfacio, voluntati meae non satisfacio. Olivae Contestanorum VI Cal. Iun. an. MDCCXLI.

\section{G. MAYANS A L.A. MURATORI, 4 DE MAYO DE 1743}

Sapientissimo viro Ludovico Antonio Muratori, Serenissimo Duci Mutinensi a Bibliotheca, Gregorius Maiansius.

Nicolai Antonii Censuram Historiarum Fabulosarum, quas statim ac evulgavi ad te misi, procul dubio iam habes et forte etiam legisti. Vide quam turbas eruditissi-

44. HÜBNER, CIL, n. 3.616; CORELL, n. 37.

45. HÜBNER, CIL,m n. 3729. 
mus vir et ego nolentes commoverimus. Adversus illius et mea scripta accusationem instituit apud supremae violatae fidei quaesitores Didacus Nicolaus Heredia, canonicus granatensis, homo superstitiosus, flevissimi et praecissimi ingenii. Illi manifestam ignorantiam despexerunt. Deinde accusator se contulit ad cardinalem Casparem Molinam, Regis Castellae Senatus Gubernatorem, qui a Ioanne Francisco de la Cueva, eiusdem Consilii senatore, instructus animatusque, accusationem audire voluit, ut condemnationi interesset atque praesset. Proposita accusatio apud regis primi Senatus decemviros totius Hispaniae gubernationi praepositos, crimen illud obiectum quod adversus laminas et membranas granatenses ab Innocentio XI proscriptas stilum converterimus Nicolaus Antonius obiter et ego paullo distinctius. Cardinalis magna voce et firmis lateribus suassit persuasitque, ut Censurarum exemplaria dispersa collligerentur, mihi manuscripta omnia, per viginti annos partim avidissime adquisita, partim per omnem vitam sumo studio elaborata, eriperentur ut, me exarmato, nullus in Hispania supersit qui vel mutire audeat tum adversus laminas et membranas granatenses, tum adversus nefanda et pudenda mendacia per chronica ficta in historiam civilem et ecclesiasticam intrusa. Uno verbo, rege inconsulto, direpta mihi centum et septem volumina manuscripta, quibus artes omnes liberales et universam historiam, hispanam praecipue, illustrare volebam, instituta in eum finem Academia, cuius ego sum censor. Academiae iussu formis typographicis imprimebatur marchionis Mondexarensis Aera Hispanica, egregium opus chronologiae stabiliendae. Suspensa etiam huius operis editio, quamqum ad eam quod attinet, remisior est cardinalis cum in illa nihil tractetur de granatensibus superstitionibus et chronicorum mendaciis. Ego Dei favore fretus nullum mei defensorem dare volui. Amici mei, partim conterriti et obstupefacti, pro me nihil audent facere, partim, etsi perpauci, vehementer laborant ut restituantur mihi manuscripta et omnibus eruditis spes legendi opera praestantissima. Sed frustra clamant. Ea de caussa ad Pontificem Maximum, tanquam ad sacram ancoram confugio. Mitto tibi exemplar litterarum quas ad eum scripsi. Peto a te, eruditissime vir, ut ad cardinales amicos tuos, et ad doctissimos viros qui Romae vivunt, literas des efficacissimas, quibus illis persuadeas ut maxime conatu consulant Reipublicae Literariae laboranti. Si Summus Pontifex me voluerit commendare Regi Catholico, principi sapientisimo et iustissimo, vel iubere cardinali Molina ut attentius consideret mea merita et caussam ipsam, exitum res sortietur felicissimum. Sin minus, actum in Hispania de literis. Si beneficio tuo alterutrum impetravero, summam a me, tui observantissimo, inibis gratiam. Praeterea, si Iosepho Cervio, qui apud regem et reginam multum valet, caussam meam commendaveris, maximi momenti erunt literae tuae. Vale, eruditorum nostri temporis princeps, et in maxima mea calamitate adiuva me, namque potes. Deus Optimus Maximus tibi mentem animumque infundat, ut mihi laboranti succurras et te incolumem servet. Olivae 4 Nonas maias anni Dominicae Nativitatis 1743 .

\section{G. MAYANS A L. A. MURATORI, 8 DE JUNIO DE 1743} S.D.

Gregorius Maiansius Ludovico Antonio Muratorio, eruditorum portasignano,

De rebus meis scripsi ad te diligenter; et cum in eodem haeream luto, iterum scribere cogor ut mihi dextram porrigas. 
Conficta chronica a Hieronimo Higuera valde consona esse plumbeis laminis anno 1595 prope Granatam in monte Vallis Paradisi repertis, quasque primus omnium legit Isidorus Garcia, societatis Iesu, optime scis et ex ipsa collatione cuilibet erit certissimum. Cum ego igitur viderem ab Innocentio XI damnatas proscriptasque laminas, existimavi rem esse magni momenti laminarum et cronicorum consonantiam referre in rebus ignoratis ab omni antiquitate. Nesciebam ego Granatae adhuc superesse aliquas laminas quas ecclesiae Montis Sancti in maxima habet veneratione, putabam enim illas omnes Romam fuisse transportatas. Ignorabam etiam Didacum Nicolaum Herediam, canonicum Montis Sancti, scripsisse vitam Petri Vaccae Castrensis, archiepiscopi granatensis, laminarum propugnatoris acerrimi, in quorum defensione ducatorum septingenta millia impendit. In eius vita multus sermo de laminis quas tanti facit Heredia ut, in Praefationis fine, ausus fuerit scribere, qualificatas esse approbatione apostolica. Ego itaque, bona fide, neminem offendere cogitans, scripsi in Vita Nicolai Antonii, damnatas fuisse laminas ab Innocentio XI. Continuo Heredia Supremum Tribunal Inquisitionis adiit, tanta animi fiducia, tanta insolentia, ut apud omnes iactitaret vetitum iri Nicolai Antonii Censura Historiarum Fabulosarum et eiusdem Vitam a me conscriptam. Verum insipientem delationem despexit iustissimum illud Tribunal cuius iussu Innocentii XI Edictum condemnans laminas in omnibus hispanis ecclesiis promulgatum fuit et postea excusum in Indice librorum prohibitorum, ut in omne aevum notum esset omnibus. Tunc Heredia, qui superos non potuit flectere, Acheronta movit, patrocinante Ioanne Francisco Cueva, Regii Castellae Senatus consiliario (uti vocant) Camerali, Granatensis Senatus quondam praeside, cardinalem Molinam adiit, Regii Castellae Concilii Gubernatorem, eique facile persuasit detraxisse me hispanorum doctissimis, infensum esse sanctorum martyrum reliquiis, manuscripta mea esse perniciosa, vigilias meas pestiferas; denique ita cardinalem permovit, ut accusatione instituta atque proposita apud senatores totius Hispaniae Gubernationis praepositos, omnes decreverit quod ipsis, prout tunc res pingebantur, visum fuit; in alia omnia eunte Andrea Gonzalezio Barcia, viro doctissimo mihique amicissimo, qui omnia Nicolai Antonii scripta eisdemque vitam a me scriptam perlegerat, praedixitque fore, ut irriderent omnes eruditi quidquid adversus Nicolai Antonii scripta et mea tentaretur, legitimo et prudenti examine non praecedente. Praevaluit tamen cardinalis auctoritas, eoque suassore et persuassore, eodemque iubente, erepta mihi centum et septem volumina manuscripta per iudicem quemdam capitalem valentini Senatus, eodem tempore Valentiae et Madridii apprehensa exemplaria excusa tam Nicolai Antonii Censurae eiusdemque Vitae, a me scriptae, quam Aerae Hispanae marchionis Mondexarensis, quae sub praelo erat iussu Academiae Valentinae quam ego institui, quaeque hac mea tempestate conterrita, dissipata est.

Coepi ego clamare, pessimo futurum exemplo in studiosorum hominum scripta sic invadi: manuscriptorum omnium a me extortorum, iustum ac legitimum dominum esse me, utpote illa, aut a me descripta, aut describi iussa, aut emta iusto pretio ab iustis dominis. Vocem extuli altissime, indignum vociferans impugnari palam Edicta Pontificia ab ecclesia granatensi Montis Sancti non debere Regium Castellae Concilium calumniosam Herediae accusationem audire, alienum esse a cardinalis Molinae dignitate eiusmodi delationes exaudire. Hic tamen, quo magis ego clamabam, conceptam iram magis coquebat augebatque, et nihilominus consiliarii omnes quibus publica iniuncta gubernatio (uno decreto Cueva promotore, qui, cum haec scribo, iam 
ad plures abiit) iustitiam meam agnoscentes secundum Michaëlis Richi, Patroni Fiscalis petitionem, decreverunt ut mihi manuscripta omnia restituerentur, tanquam ad accusationem minime pertinentia. Et tamen manuscripta mihi nondum restituuntur, cardinale Molina remoram faciente, qui, ut mihi eriperentur, extraordinarium misit cursorem. Eiusdem cardinalis metu durat instituta adversus me accusatio, quam senatores omnes aversantur, quamque ego contestari nolui, nec enim alium, quam Deum, defensorem volo; et tamen ipse cardinalis durationis caussam in illos reiecit, quemadmodum ad me ipse scripsit, adiungens hostem esse me doctorum hominum Hispaniae et predicatorem exterorum, quos, ut ipse ait, gigantes puto, cum re vera non sint. Ego, sapientissime Ludovice Antoni Muratori, nonnullos exteros qui hodie vivunt laudavi, humanitate exigente, ipsorumque meritis postulantibus. Hispanos quam plurimos non solum defunctos, sed vivos, latentes, aut ignotos, ad coelum extuli meritissimis laudibus. Plusquam triginta hispanorum memoriam posteritati commendavi illorum scriptis praestantissimis in lucem emissis. Plura emittere cogito, Academia instituta in hunc finem. Denique nemini me infessum praebui nisi mendacissimis nebulonibus qui sunt docti homines, quos cardinalis vellet laudatos, ut praeclare ostendit, cum Petri Caesaraugustani Chronicon per fragmenta disseminari caeptum eodem illo artificio, quo usus Higuera in aliis Chronicis spargendis, patrocinatus est, dicente me et probante per longa et gravissima censura, confictum esse, et non solum Hispaniarum gloriae, sed catholicae religionis contrarium.

Sperabam ego, accusationem despiciendam statim ac sciretur et in notitiam publicam veniret, propugnare me Edicta Pontificia, atque eadem palam oppungari. Sed amici mei scripserunt mihi adversarios obiecere, debuisse me distinguere laminas arabice ab iis quae latine scriptae sunt; illas, non has, damnatas fuisse; miseruntque mihi Herediae librum, ubi quatuor laminas repraesentat eadem forma literarum qua in tabulis plumbeis scriptae sunt. Literarum forma ea est quam videre potes apud Antonium Ciancam in Vita sancti Secundi, lib. 1, cap. 16 et in fine Prologi quem Blasius Antonius Nassarre praemisit Christophori Rodriguezii Bibliothecae Universali de Polygraphia hispana. Literarum scilicet forma cerebrina, quae nullo unquam tempore in usus fuit, ut primo intuitu figmentum appareat. Laminarum inscriptiones eae sunt, quas videre poteris apud memoratum Ciancam, qui descripsit eas eodem anno 1595 quo apparuerunt. Leguntur etiam apud Gregorium Lopezium Maderam in Discursibus Montis Sancti granatensis, cap. 1, apud Franciscum Bermudezium Pedrazam in Antiquitatis et excellentiarum granatensium, lib. 4, cap. 11, editionis anni 1608 et in Historia Granatensi, parte IV, cap. 117 et 118, apud Iacobum Bledam in Chronico, lib. 7, cap. 35, aliosque. Atque hae sunt lamina quas Heredia ait qualificatas esse approbatione Apostolica. Sed, ut oculis tuis rem omnem subiiciam, prima lamina fideliter a me lecta et descripta, sic habet:

Corpus: ustum: divi Mesitonis martiris passus est sub Neronis imperatoris potentatu...

Eruditissimus Ioannes Baptista Perezius, ut videre potes apud Bledam, aiebat nullum martyrologium nullamque historiam mentionem fecisse Mesitonis. Adde laminam eum appellare divum, quo nomine eo tempore ethnicis solum utebantur, ita vocitantes suos deos et in eorum numerum relatos. Observa pessimum scribendi et interpungendi modum a Neronis tempore alienissimum: verborum structuram parum latinam. Praeterea vide quis unquam dixerit $s u b$ Neronis potentatu, etsi vocem hanc 
latinam, ut plane est, fateor. Denique considera an sufficiat haec sola inscriptio, ut Mesitonis cineres tanquam sacri colatur cum verum sit hanc laminam cum caeteris a Summo Pontifice damnatis inventam fuisse, sed hoc alii, quorum interest, iudicent atque decernant. Ego de sanctorum cultu non disputo, sed de laminarum falsitate. Etsi quid ex hoc consequatur, facile vides.

Secunda lamina sic habet. «Año secundo Neronis imperii calendas aprilis: pasus est martirium: in hoc loco illipolita...us Thesiphon: dictus priusquam converteretur Abenathar. Dicti Iacobi Apostoli discipulus vir literis et sanctitate preditus plumbi tabulis escripsit librum illum Fundamentum Eclesiae appellatum: et simul pasi sunt sui discipuli: divus Maximinus: Luparius quorum pulvis: et liber sunt cum pulveribus divorum martirum in huius sacri mont.. cavernis: in eorum memoriam venerentur. F.C.P.C. Florenti. Illiberitan».

Iniquus essem eruditioni tuae, si minima persequerer. Omitto igitur inscriptioni vitia novitatem recentissimam indicantia, generalem illam et affectatam loci illipulitani mentionem, loquutiones barbaras. Vides in Hispania, silente omni antiquitate, ut fatebatur ipse Petrus Castrensis, iam fuisse martyres anno secundo imperii Neronis, priusquam Romae post octennium neroniana inciperet persecutio omnium prima, unde Orosio, hispano scriptore referente, in ceteras provincias dimanavit. Vides ut martyres celebrari Maximinum et Luparium, ignota nomina. Animadvertis Granatam cognominari coloniam Florentinam Illiberitanam per allusionem ad male lectam et intellectam inscriptionem Alcazavae (qui vicus est granatensis) repertam anno 1540, ut testatur Alexius Venegas in notis ad Alvarum Gomezium de Militia principis Burgundi, quam inscriptionem emendatiorem quam Venegas et Gruterus, pag. CCLXXII, n. 7, edidit Ferdinandus Mendoza, lib. 1, cap. 1, De concilio Iliberitano confirmando. Sed praeter caetera in mentem revoca anno 1588 inventas fuisse Granatae (ut ferebatur) in Turri Turpiana reliquias quasdam inter quas numerabatur praecipuumque locum tenebat membrana quaedam quam perbelle descripsit Franciscus Bermudezius Pedraza, Antiquitatis et excellentiarum granatensium, lib. 4, cap. 2, membrana illa, ut videmus apud eundem, cap. 3, scripta fuit a sancto Cecilio duabus linguis, arabica et castellana eo tempore nondum usu recepta, imo nec inventa nec excogitata, et tamen inaudita miracula, divinitus edocto futurae linguae usu, hac ipsa lingua ipse sanctus Caecilius se subscripsit granatensem episcopum ante Granatam conditam. Quae omnia, quia miraculo erant, ut miracula habebantur Aldretio, Bivario et quam plurimis aliis. Quoniam vero alii longe sapientiores et cautiores, exceperunt arabicam linguam in usu non fuisse in Hispania Neronis tempore, ut huic dificultati obviam iretur, conficta fuit haec lamina in qua Cthesiphon dicitur appellatus antea Abenathar. Praeterea fictus fuit liber de essentia Dei, cuius titulus, teste Pedraza granatensi illius temporis scriptore, sic habebat: Liber de essentia Dei, quem divus Thesiphon Apostoli Iacobi discipulus in sua naturali lingua arabica Salomonis characteribus scripsit et alium Fundamentum Ecclesiae appellatum, qui in huius sacri montis caverni iacet. Deus a Nerone imperatore hos duos liberet libros; imposuit finem hic: et in suis operibus scribens miracula, et vitae integritatem sui magistri-vi-in huius sacri montis ca-essi. Ride, si lubet, aut mecum potius indignare. Optime nosti librum illum, Fundamentum Ecclesiae appellatum, condemnatum fuisse ab Innocentio XI. Ergo lamina, quae illius libri mentionem facit, scripta fuit post recentissimam eiusmodi libri fictionem. 
Praetereo multa argumenta veritatem hanc confirmantia, quae si adducerem, iustum librum scriberem.

Tertia lamina sic habet: «Año secundo Neronis imp.rii Marc. Cal.ndis: pasus fuit martirium: in hoc loco ilipulitano: electus: adhuc effectum: sanctus Hircius: apostoli Iacobi discipulus: cum suis discipulis: Turilo: Panuncio: Maronio: Contulio: per medium ignem in quo vivi ambusti fuerunt: eternam vitam petentibus transivere: ut lapides in calcem conversi fuerint quorum pulvis in hujus sacri montis cavernis iacent qui ut ratio postulat in eorum memoriam veneretur...»

Haec lamina etiam refert sancti Hiscii martyrium a Neronis imperii annum secundum, eique comites adiungit in gloriosissimo praelio Turilum, Panuncium, Maronium, Centulium, ecclesiasticae antiquitati incognitos. Omitto stili et scripturae barbariem. Festino enim ad laminam quartam, quae sic se habet.

«Ano secundo Neronis imp. calendis februari: pasus est martirium, in hoc loco ilipulitano divus Cecilius sancti Iacobi discipulus: vir literis linguis et santitate preditus: prophetias divi Ioanis: apostoli comentavit. que sunt posite cum aliis reliquiis: in sublimi parte inhabitabilis Turri Turpiane: sicut dixerunt mihi sui discipuli divus Setentrius et Patritius qui cum illo passi sunt: quorum pulveris iacet in huius sacri montis cavernis: in quoru. memoriam beneretur».

Nesciebamus antea santum Caecilium sancti lacobi fuisse discipulum, credebatur enim fuisse Apostolorum Petri et Pauli, a quibus si cum aliis sociis qui inter confessores numerantur, Roma in Hispaniam missus est, non antea venire potuit quam Petrus et Paulus simul essent, et si postea martyrii palmam consequutus est, eam dipisci non potuit anno, ut dicitur, secundo imperii Neronis. Verum laminarum auctor assuetus, vel fingere, vel ficta ab aliis describere inter sancti lacobi discipulos Caecilium numeravit secutus librum apocryphum Calixto Secundo tributum. Sed quo magis mirere, ait ipsa lamina Caecilium commentarium edidisse in Ioannis Apostoli prophetias, quem viventem adhuc prophano tunc vocabulo Divum appellet. At quaenam illae prophetiae? Non Apocalipsis, quam Ioannem Evangelistam scripsisse scimus post quartum decimum annum imperii Domitiani, sed pseudoprophetias illas, quas e lingua hebrea in graecam Dionysius Areopagita, e graeca in hispanam, qualis erat in usu tempore Philippi Secundi, transtulit Caecilius, qui praefationem praemisit arabice scriptam et commentarium subiecit eadem lingua, non illa quidem antiqua, sed quae Granatae in usu erat cum apparuerunt laminae. Operae pretium est legere Pedrazam, Antiquitatis et excellentiarum granatensium, lib. 4, cap.2 et 3, et Aldretem in Antiquitatibus Hispaniae, lib. 2, cap. 9 et seqq. Sed pergamus. Hae prophetiae (teste laminae auctore, cuius fide haec omnia nituntur) sunt posite cum aliis reliquiis: in sublimi parte inhabitabilis Turri Turpiane. Mirum est prophetias in sublimi parte positas, et nullo unquam tempore expositas, perdurare potuisse quindecim saecula, cum nihil facilius diruatur quam fortissimorum aedificiorum pars superior, ut membranae taceam debilitatem temporis iniuriis obnoxiam, praesertim si aëri sit impervia, qua ratione citius ac facilius corrumpitur. Sed turris erat (ride si sapis) structurae phoeniciae, testantibus architectis, quibus laminarum fautores facile fidem adhibuerunt. Eadem lamina vocat turrim inhabitabilem ad diluendum argumentum eorum qui obiecerant, quo tandem modo accidere potuit, ut in turri illa tantopere frequentata, utpote qua utebatur ecclesia vetus granatensis, tandiu latere potuissent prophetiae illae in sublimi parte positae. Ego scire vellem quomodo turris, quae post tot saecula habitabilis 
erat, antea esset inhabitabilis? Nam si aiunt renovatam, difficilior erit conservatio membranae.

Sed videamus quaenam illae reliquiae sint quae cum prophetiis positae fuerunt. Videlicet eae ipsae reliquiae, quae in fine chartae membranaceae, quae prophetias continebat, recensentur a nescio quo, qui testatur sanctum Caecilium morti proximum sibi commendasse ut eas custodiret ne in maurorum potestatem pervenirent. Praevidebat scilicet Caecilius membranae inauditam durationem et maurorum in Hispaniam adventum et dominationem. Audiamus postrema verba ipsius membranae. Reliquiae quae hic extant, sunt: Prophetia sancti loannis Evangelistae de fine mundi. Dimidia pars lintei quo Virgo Maria suorum oculorum lacrimas abstersit in sui sacrosanti filii Passione. Os sancti Stephani protomartyris.

Ergo habemus reliquias quas memorat membranae scriptor, qui fuit idem ac laminae, esse primo loco, sancti Ioannis pseudoprophetias ab Innocentio undecimo damnatas; secundo loco, Mariae Virginis linteum, cuius altera pars angularis Granatae, altera etiam angularis, ut quadrangulum utraque effi(ci)ant in America divinitus reperta est, si credimus Herediae alleganti tabularium montis sancti. Tertio denique loco, inter reliquias numerantur tibia sancti Stephani, Granatae condita quadringentos annos antequam Protomartyris indubitatae reliquiae divinitus inveniretur. Sed quid verbis opus est? Hae sunt reliquiae quas laminarum fide innixus veras esse pronunciavit, Benedicto Aria Montano, Ioanne Baptista Perezio, Petro Valentia, Ioanne Mariana, aliisque piis et eruditis viris id improbantibus, archiepiscopus granatensis Petrus Castrensis, cuius sententiam lectu dignissimam videre poteris apud Pedrazam, lib. 4, cap. 14, et apud Herediam, qui in suffragatoribus extollendis multam operam posuit, etsi Benedictum Ariam Montanum, Ioannem Marianam aliosque iniuria inter eos numeravit. Exstat hodie in montis sancti ecclesia inscriptio posita iussu Petri Castrensis, innititur illa laminarum fide et manifeste alludit ad illa verba quartae laminae: sicut dixerunt mihi sui discipuli di(v)us Selentrius et Patricius, qui cum illo passi sunt. In mentem mihi nunc venit illud Hieremiae: Prophetae prophetabant mendacium. Nosti caetera. His praetermissis, ex superioribus verbis evincitur, laminarum auctorem vixisse Neronis tempore, cum a martyribus, quos passos esse ait anno secundo imperii illius haec se accepisse testetur. Sed cum ipse alleget prophetias, quae Lutheri meminerunt, oportet eas scriptas fuisse post Lutherum, igitur prophetiarum etiam Caecilianus commentarius; ergo et ipsa lamina quae prophetias et commentarium laudat; ergo caeterae etiam laminae, scriptae eadem characterum specie eadem barbarie, iisdem scribendi vitiis eisdem loquendi formulis, eisdemque inauditarum rerum falsissimis narrationibus ibidemque repertae, $i(n)$ ventioni dante operam Sebastiano Lopezio, homine pessimis artibus dedito, quem ad fodiendum impie fingitur hortata fuisse ipsa Dei mater, referente ipso Heredia in suo Mystico sert, pag. 61.

Et tamen ego, quia laminarum falsitatem notavi generalibus verbis referens lectorem ad Innocentii XI Edictum, et nullam reliquiarum neque mentionem, neque allusionem faciens, semel et iterum accusatus sum, ut impius apud laesse reliquionis quaesitores, qui calu(m)niatorem despexerunt. Accusor ab eodem apud Regium Senatum, et accusatio pendet, me interea privato manuscriptis meis, et interdicta lectione Nicolai Antonii verarum Hispaniae laudum certissimi et gloriosissimi vindicis. Cardinalis Molina, Regis Consilii Gubernator, qui ef(f)renem Herediae licentiam reprimere debebat, eum incitavit, meque pessime tractavit et tractat, enumerans me inter doc- 
torum Hispaniae hominum hostes, cum nemo magis quam ego literatos amet, laudet, celebret. Consiliarii regii hoc vident, mihique cupiunt favere, sed eorum favorem impedit summa eius potentia cum maximorum numerum auctoritate coniuncta. Mihi absentia optimum iustissimmque regem confugium perquam difficile.

Haec cum ita sint, eruditissime Ludovice Antoni Muratori, rem mihi gratissimas facies, si qua vales auctoritate, effeceris ut ex Urbe Roma aliqui cardinales, aut viri dignitate praestantes, caussam meam, meque ipsum commendent cardinali Molinae, aut saltem scribant Duci Adriae et marchioni Scotto, qui apud eum plurimum valent, ut patrocinium meum suscipiant. Praetereo gratias scribere poteris Iosepho Cervio ob egregia officia erga me, quae ut maiora et efficaciora mihi praestet, suis meritis perficies. Denique viribus omnibus incumbe ut cardinalis despiciat accusationem hanc mihi molestam, Nicolai Antonii memoria indignam, Edictis Pontificiis contrariam, minimeque dignam quae inter christianos audiatur. Id non meis meritis, sed veritatis amori et christiane charitati praestare debes. Vale, vir sapientissime, et caussam meam ita defende ut ipsa postulat. Oliva 8 Idus Iun. ann. 1743.

BMV, Serrano Morales 7272-41 y 7271-47. 